Article

\title{
Analysis of Tribological Properties in Disks of AA-5754 and AA-5083 Aluminium Alloys Previously Processed by Equal Channel Angular Pressing and Isothermally Forged
}

\author{
Carmelo J. Luis Pérez *, Rodrigo Luri Irigoyen, Ignacio Puertas Arbizu *, Daniel Salcedo Pérez, \\ Javier León Iriarte and Juan P. Fuertes Bonel \\ Materials and Manufacturing Engineering Research Group, Engineering Department, Public University of \\ Navarre, Campus Arrosadía s/n, 31006 Pamplona, Navarra, Spain; rodrigo.luri@unavarra.es (R.L.I.); \\ daniel.salcedo@unavarra.es (D.S.P.); javier.leon@unavarra.es (J.L.I.); juanpablo.fuertes@unavarra.es (J.P.F.B.) \\ * Correspondence: cluis.perez@unavarra.es (C.J.L.P.); inaki.puerta@unavarra.es (I.P.A.); \\ Tel.: +34-948-169-301 (C.J.L.P.); +34-948-169-305 (I.P.A.)
}

Received: 8 June 2020; Accepted: 9 July 2020; Published: 11 July 2020

\begin{abstract}
In the present study, the wear behaviour of two aluminium alloys (AA-5754 and AA-5083) is analysed where these have been previously processed by severe plastic deformation (SPD) with equal channel angular pressing (ECAP). In order to achieve the objectives of this study, several disks made of these alloys are manufactured by isothermal forging from different initial states. The microstructures of the initial materials analysed in this study have different accumulated deformation levels. In order to compare the properties of the nanostructured materials with those which have not been ECAP-processed, several disks with a height of $6 \mathrm{~mm}$ and a diameter of 35 $\mathrm{mm}$ are manufactured from both aluminium alloys (that is, AA-5754 and AA-5083) isothermally forged at temperatures of 150 and $200{ }^{\circ} \mathrm{C}$, respectively. These thus-manufactured disks are tested under a load of $0.6 \mathrm{kN}$, which is equivalent to a stress mean value of $18 \mathrm{MPa}$, and at atational speed of $200 \mathrm{rpm}$. In order to determine the wear values, the disks are weighed at the beginning, at 10,000 revolutions, at 50,000 revolutions and at 100,000 revolutions, and then the volume-loss values are calculated. This study was carried out using specific equipment, which may be considered to have a block-on-ring configuration, developed for testing in-service wear behaviour of mechanical components. From this, the wear coefficients for the two materials at different initial states are obtained. In addition, a comparison is made between the behaviour of the previously ECAP-processed aluminium alloys and those that are non-ECAP-processed. A methodology is proposed to determine wear coefficients for the aluminium alloys under consideration, which may be used to predict the wear behaviour. It is demonstrated that AA-5754 and AA-5083 aluminium alloys improve wear behaviour after the ECAP process compared to that obtained in non-ECAP-processed materials.
\end{abstract}

Keywords: wear; ECAP; SPD; aluminium alloys

\section{Introduction}

A great deal of attention has been paid over the past several years to the severe plastic deformation (SPD) processes of metallic materials, where the so-called equal channel angular pressing (ECAP) stands out [1]. Nevertheless, the number of studies which deal with the evaluation of tribological properties is relatively scant. Most of these research studies deal with the wear behaviour of aluminium and copper alloys which are ECAP-processed. Because of the grain refinement that takes place with 
SPD processes, mechanical strength and hardness are increased and thus their wear behaviour is also expected to be improved [2].

In the tribological behaviour of interfaces, there are several aspects to be taken into account, such as: surface morphology, hardness and surface roughness, among others. In addition to this, it is also important to understand the mechanisms which control the friction at the contacts of materials. Sandeep and Senetakis [3] investigated the influence of elastic properties and surface morphology on the inter-particle friction of natural soil grains, where the tests are carried out with a custom-built micromechanical equipment and with a load which ranges from 1 to $5 \mathrm{~N}$. These authors found that the inter-particle coefficient of friction is inversely correlated with the Young's modulus and the surface roughness. Ni and Zhu [4] studied the micro tangential deflection of the interface of mating machined surfaces subjected to normal and tangential forces. It was shown that contact interface subjected to a tangential force undergoes elastic deformation, plastic deformation and micro slip before breakaway takes place. In line with this, Sandeep and Senetakis [5] also investigated the inter-particle tangential force-displacement behaviour of a broad range of granular materials and they show that the microslip displacement increases with the increase in normal force. Moreover, they propose a modified expression which is able to predict the slip displacement of the geological materials by taking their micro-hardness into consideration. A remarkable study by Greenwood and Tripp [6] exists, in which a general theory of contact between two rough plane surfaces was given. Medina et al. [7] proposed a simple analytical model which predicts that the tangential stiffness is proportional to normal load but, on the other hand, independent of asperity radius and Young's modulus. This model shows good agreement with a full numerical analysis at low normal loads but, at high normal loads, it has to be somewhat modified, which is also shown in the same study.

In the existing bibliography, there are several studies which focused on the wear behaviour of diverse aluminium alloys, such as the ones by Thuong et al. [8], El Aal et al. [9,10] and Chegini et al. [11], among others. A semi-solid-cast hypoeutectic aluminium alloy (Al-7Si-Mg) was analysed in the research study by Thuong et al. [8], where the initial material is obtained both by cooling slope casting and by conventional casting and then it is subjected to ECAP. The aluminium alloy is ECAP-processed four times at room temperature with route A and the ECAP die has an angle between channels of $120^{\circ}$. One of the most important conclusions of this research study is that the wear resistance turns out to be higher in the case of the cooling slope-cast ECAPed samples than in the conventionally cast ECAPed ones. In addition, in both study cases, the wear resistance of the aluminium alloy improves compared to the non-ECAP-processed samples.

On the other hand, in the research studies by El Aal et al. $[9,10]$, the wear properties of ECAP-processed Al-Cu alloys were studied by pin-on-disk dry sliding wear tests. It was found in El Aal et al. [9] that the wear resistance of these aluminium alloys (with a copper content of $2 \%$, $3 \%$ and $5 \%$ ) improves with the number of ECAP passages as well as with the copper content. Another conclusion was that the wear mass loss is more affected by the sliding distance values used in the tests (268.6 and $537.2 \mathrm{~m}$ ) rather than by the load values (19.6 and 29.4 N). In the research by El Aal [10], the effect of the pre-homogenization heat treatment on ECAP-processed Al-Cu alloys (with copper content values of $2 \%$ and $3 \%$ ) was analysed, where these aluminium alloys are homogenized at a temperature of $550{ }^{\circ} \mathrm{C}$ for 7 days. The ECAP process is carried out at room temperature with route A and the homogenized samples are subjected to nine passages (for the alloy with the copper content of $2 \%$ ) and to eight passages (for the alloy with the copper content of $3 \%$ ). Nevertheless, in the case of the non-homogenized samples, it is only possible to carry out a maximum number of six ECAP passages. It may be observed that the homogenized $\mathrm{Al}-\mathrm{Cu}$ alloys show better wear resistance than the non-homogenized ones.

As was mentioned earlier, another notable study is the one by Chegini et al. [11], where the wear behaviour of ECAP-processed AA-7075 was examined. Billets with a diameter of $19.1 \mathrm{~mm}$ and with a height of $140 \mathrm{~mm}$ are ECAP-processed four times at room temperature using route $\mathrm{Bc}$. It is shown from the pin-on-disk wear tests that the wear resistance of AA-7075 is considerably increased because of the 
grain refinement with the ECAP process. In addition, wear mass loss increases when the load applied in the wear tests $(10 \mathrm{~N}, 20 \mathrm{~N}$ and $30 \mathrm{~N})$ is increased [11]. Manjunath et al. [12] studied the improvement in the wear resistance of ECAP-processed Al-5Zn-2Mg alloy. In addition to this, these authors found that the friction coefficient is decreased after four ECAP passages, with route Bc at low temperature. Another remarkable piece of research is that by El Aal and Kim [13], where these authors analysed the wear properties of HPT-processed Al-7\%Si alloy through ball-on-flat surface reciprocating sliding wear tests. As a consequence of HPT (High Pressure Torsion), wear resistance of Al-7\%Si alloy is improved and the friction coefficient is decreased.

Regarding the wear resistance of ECAP-processed copper alloys, Li et al. [14] studied the tribological properties of a commercial copper alloy with a zirconium content of $0.1 \%$. Billets of this alloy are subjected to 2, 4 and 8 ECAP passages at room temperature with route Bc. After the ECAP process, the samples are machined into disks with a thickness value of $1.5 \mathrm{~mm}$. The micro-wear tests are performed with a ball-on-disk dry sliding configuration, where the ball for the experiments is made of stainless steel and it has a diameter of $1.6 \mathrm{~mm}$. One of the most important conclusions is that the ECAP-processed $\mathrm{Cu}-\mathrm{Zr}$ alloy shows a higher wear resistance than the non-ECAP-processed alloy. Furthermore, the ECAP processing leads to a decrease in the friction coefficient due to an improvement in the mechanical properties, where the higher the applied normal load is, the greater the decrease in the friction coefficient turns out to be [14].

Another notable research work on ECAP-processed copper is the one by Zhilyaev et al. [15]. These authors studied the wear properties of three different cases of ultra-fine grained (UFG) pure copper, which are as follows: a first combination of machining and high-pressure torsion (HPT), a second combination of ECAP and HPT and a third combination of ECAP, machining and HPT. The machining process is used to generate the chips which are subsequently consolidated by HPT at room temperature. One of their conclusions is that the three previously mentioned cases show higher wear rates compared to the initial copper material, which is coarse-grained [15]. Purcek et al. [16,17] studied the influence of HPT followed by a subsequent artificial aging treatment at $450{ }^{\circ} \mathrm{C}$ for $1 \mathrm{~h}$ on the tribological properties of a $\mathrm{Cu}-\mathrm{Cr}-\mathrm{Zr}$ alloy. The corresponding friction and wear tests are carried out using a tribometer with reciprocating ball-on-disc contact configuration, where the most significant result is that the combination of both HPT and artificial aging increases wear resistance and reduces the friction coefficient of the Cu-Cr-Zr alloy. Furthermore, these authors analysed the influence of temperature on the previous tribological properties and, in order to do this, they performed the wear tests at 25,200 and $400{ }^{\circ} \mathrm{C}$ [17].

Two worthwhile studies which dealt with the wear behaviour of ECAP-processed pure titanium are those by Stolyarov et al. [18] and by Wang et al. [19]. Stolyarov et al. [18] compared the friction coefficient of ultra-fine grained titanium in relation to its coarse-grained form. The UFG titanium is manufactured in two different states: eight passages of ECAP at a temperature range from 400 to $450{ }^{\circ} \mathrm{C}$ with route $\mathrm{Bc}$ and this ECAP process but followed by an additional cold rolling process. It may be observed that UFG titanium possesses a lower friction coefficient in relation to coarse-grained titanium and thus wear behaviour is improved. As was mentioned earlier, Wang et al. [19] carried out a study on the wear properties of HPT-processed pure titanium with a TiN coating of around $2.5 \mu \mathrm{m}$. Wear tests show that there is an improvement in wear resistance of TiN coatings by physical vapour deposition (PVD) when UFG titanium (in this particular case, by HPT) is used as the substrate.

Regarding ECAP-processed magnesium alloys, Patil et al. [20] dealt with the effect of ECAP on the wear behaviour of a Mg-Zn-Gd-Zr alloy, which is subjected to three passages at a temperature of $380^{\circ} \mathrm{C}$. The wear tests are performed with a pin-on-disk tribometer at room temperature. In the wear rate tests at $10 \mathrm{~N}$, the influence of ECAP is beneficial but in the case of wear rate tests at higher loads $(20 \mathrm{~N}$ and $30 \mathrm{~N})$, the ECAP process has a negative effect.

It appears that little attention has been paid to the wear behaviour of ECAP-processed steels. Along these lines, Huang et al. [21] studied the tribological properties of low carbon steel with a carbon content of $0.2 \%$ which is ECAP-processed four times at a temperature of $400{ }^{\circ} \mathrm{C}$ using route B. One of 
the most significant conclusions is that the grain size refinement of the ECAP-processed low carbon steel leads to both a decrease in the friction coefficient and an increase in wear resistance.

Finally, in the study by Luis Pérez et al. [22], mechanical cams were isothermally forged from two different initial states: annealed AA-5083 and AA-5083 ECAP-processed twice with route C. These two types of cams were then subjected to an in-service wear test through specific equipment with a block-on-ring configuration developed for such purpose. From the experimental results, it is observed that that the ECAP-processed cams have lower wear values (15.38\%) than those only annealed and then forged.

In this present study, the wear behaviour of AA- 5754 and AA-5083 is analysed where these have been previously processed by severe plastic deformation with ECAP at room temperature. A comparison is made between the behaviour of the previously ECAP-processed aluminium alloys and those that are non-ECAP-processed, where it has been observed that the previously ECAP-processed ones show a higher value of wear resistance than those which are non-ECAP-processed. This research study was carried out using specific equipment developed for testing the in-service wear behaviour of mechanical components [22], which are considered to have a block-on-ring configuration. The strain distribution of the ECAP-processed and forged aluminium alloys under consideration is calculated using a new flow rule proposed in [23]. Strain rate will be more influential when temperature increases, but as was previously mentioned, these present wear tests are performed at room temperature and as the material is lubricated, the increase in its in-service temperature will not be significant. Biswas and Kailas [24] analysed the wear behaviour of titanium and copper in terms of strain rate and temperature and they concluded that the strain rate response of these may be a good indicator of both wear resistance and wear mechanism. In line with this idea, in another research study by Kailas and Biswas [25], they affirmed that the surface and subsurface morphology of abraded titanium, copper and aluminium depend on the specific microstructural response of them to the strain rate and temperature values considered. Furthermore, Chelliah and Kailas [26] studied the wear behaviour of titanium and one of their most remarkable conclusions is that wear rate is essentially based on the synergy between tribo-oxidation/tribo-chemistry and strain rate response in the near surface region. Kumar et al. [27] analysed the tribological properties (wear resistance and corrosive wear) of AZ31 magnesium alloy predeformed at low and high strain rate values, and they observed that the hardness of the samples decreases with an increase in the strain value, which also affects the wear resistance. The deformation at the lower strain rate value leads to a lower decrease in hardness and, therefore, samples deformed at the higher strain rate value show a lower resistance to corrosive wear. Finally, some other research studies in relation to the influence of high temperature on wear behaviour are as follows. Rajaram et al. [28] studied an Al-Si alloy obtained by stir casting as a potential high temperature structural material. Its tensile and wear properties were investigated at various temperatures from room temperature to $350{ }^{\circ} \mathrm{C}$, where these authors found that the strain hardening exponent decreases with the increase in temperature due to thermal softening phenomenon. It was also observed from wear tests that there is an increase in wear resistance when temperature is increased. Rajaram et al. [29] also studied the wear behaviour of both an Al-Si alloy and an Al-Si/graphite composite at room and elevated temperatures. They obtained a decrease in wear rate with an increase in temperature, where this observed effect is because of the oxide film formation, which becomes faster at higher temperature values. Another interesting study on the influence of high temperature on wear behaviour is the one carried out by Kumar et al. [30] in which these researchers analysed the effect of fly ash particulate on high temperature dry sliding wear resistance of AA-6061. This composite metallic material is developed by powder metallurgy and hot extrusion and it is subjected to pin-on-disc tests at room temperature, 100,200 and $300{ }^{\circ} \mathrm{C}$. One of the main conclusions is that the addition of fly ash to AA- 6061 increases the temperature of mild-to-severe wear transition up to $300^{\circ} \mathrm{C}$. 


\section{Experimental Set-Up}

In order to determine the wear that materials undergo when there are contacts with relative movement between parts, the following types of tribometers may be used: ball-on-disk, pin-on-disk, pin-on-ring or block-on-disk, among others [31-34]. As is well-known, these wear testing devices are very useful in assessing the wear behaviour of mechanical elements under accelerated conditions. For example, Fernandes et al. [31] did research into the friction film on the performance of a dry automotive clutch system. They used a pin-on-disc tribometer in order to determine both the friction coefficient and the wear rate. $\mathrm{Xi}$ et al. [32] studied the contact problems between wheel and rail that take place in a railway system. In order to do this, they used a commercial ball-on-disc tribometer and it may be affirmed that all the possible creepages involved in railway systems can be easily analysed in this way. Pürçek et al. [33] used a block-on-ring tribometer in order to carry out dry sliding friction and wear tests on zinc-based alloys: four zinc-aluminium alloys and an SAE 660 bronze as there is a great deal of interest in these in terms of their forming part of mechanical elements as sliding bearing materials. As another last practical example of tribometer configuration, one could mention the research work by Kim et al. [34], where they simulated the progressive accumulation of wear in oscillating metal on metal contacts. A reciprocating pin-on-disk tribometer was used by these authors so that these previously obtained wear results were employed to simulate a block-on-ring experiment by finite element modelling (FEM) simulations.

As was previously mentioned, in order to carry out this present study, a piece of equipment was specifically developed. This equipment is shown in Figure 1. As can be observed, it may be considered to have a block-on-ring configuration [22].
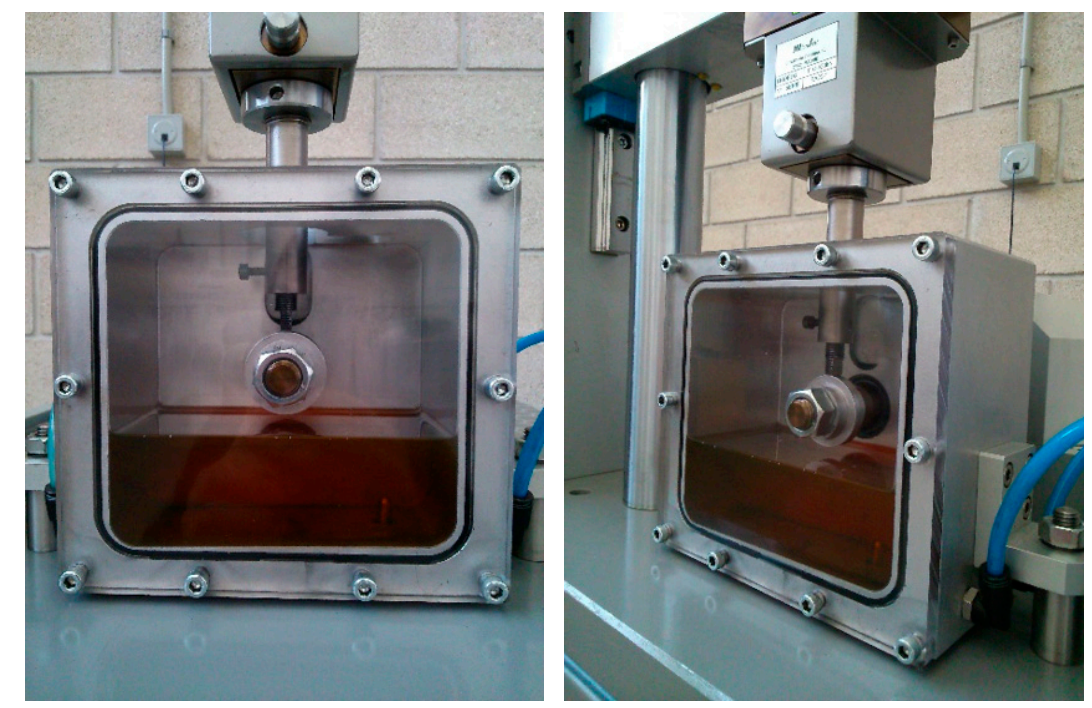

Figure 1. Equipment employed for testing the disks.

The samples to be tested consisted of rings with an external diameter of $35 \mathrm{~mm}$ and the block had a contact surface with a curvature radius $r=17.5 \mathrm{~mm}$. The ring and the contact block are shown in Figure 2. As can be observed in this figure, the thickness of the ring used is $6 \mathrm{~mm}$. This geometry was used because it is a symmetrical wear test and thus, the apparent contact area is always the same regardless of the force which is applied. The exerted pressure and the rotational speed may be varied and thus the wear behaviour of the pair of materials in contact may be evaluated. 


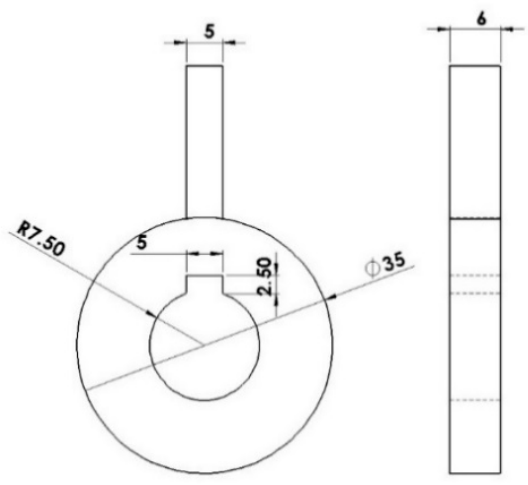

Figure 2. Disk designed to determine the material wear.

In this present research work, the aim of these tests was to evaluate the wear behaviour of ultrafine grained materials obtained by a severe plastic deformation process (Equal Channel Angular Pressing, ECAP) compared to those without ultrafine grain size. In order to do this, several disks from both materials were manufactured. In this study, aluminium alloys AA-5083 and AA- 5754 were specifically tested in contact with a follower made of quenched and tempered carbon steel.

As was previously mentioned, to study the effect of the microstructure on the wear behaviour, disks of both aluminium alloys at different states were manufactured. The previously ECAP-processed disks were named as AA-5083-N2 and AA-5754-N2, and they were manufactured following the procedure which is shown in Figure 3.

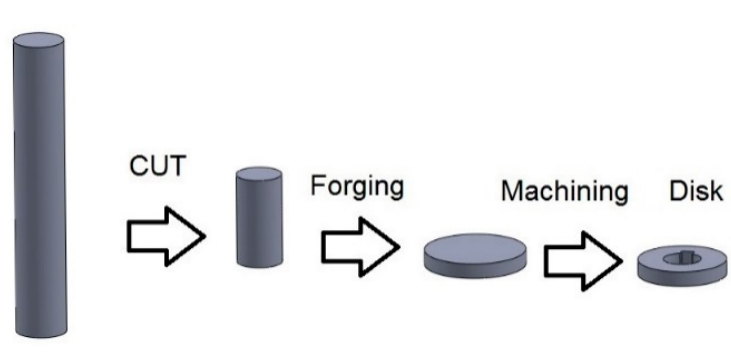

(a)

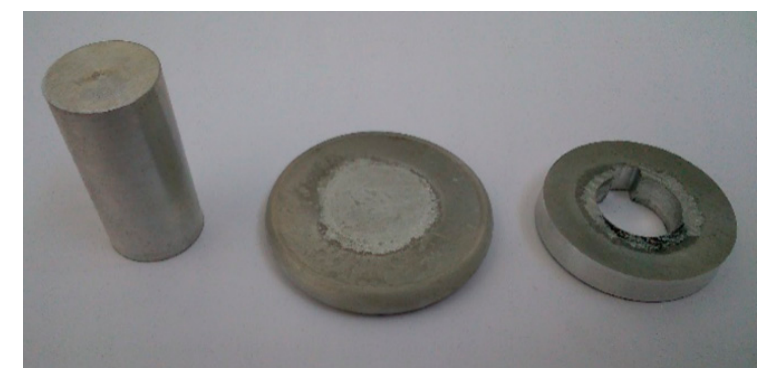

(b)

Figure 3. Steps for the manufacturing process of the disks (a) and test disks finally manufactured (b).

First, billets of AA-5083 and AA-5754 with $20 \mathrm{~mm}$ in diameter and $100 \mathrm{~mm}$ in length were ECAP-processed twice at room temperature using route $C$, where this route consisted of rotating the material billet 180 after each passage. The ECAP process was carried out with an extrusion press located at the Public University of Navarre (Spain) and at a velocity of $50 \mathrm{~mm} / \mathrm{min}$. The ECAP die employed had a circular cross-section with a diameter of $20 \mathrm{~mm}$, where this also had equal fillet radii with a value of $5 \mathrm{~mm}$ and the angle between the entrance channel and the exit channel was $90^{\circ}$.

Subsequently, from the ECAP-processed material, preforms $18 \mathrm{~mm}$ in diameter and $36 \mathrm{~mm}$ in length were machined and then isothermally forged at 150 (for AA-5754) and $200{ }^{\circ} \mathrm{C}$ (for AA-5083). Figures 4 and 5 show several SEM micrographs for isothermally-forged AA-5083 and AA-5754, respectively, at different initial deformation states: annealed and ECAP-processed. As can be observed in the case of both aluminium alloys, the forging process of the ECAP-processed samples produced a finer and more homogeneous microstructure in relation to the annealed ones [23]. In the case of the ECAP-processed and subsequently forged AA-5083, an increase from 107.5 to $118.6 \mathrm{HV}$ (that is, of $10.3 \%$ ) was obtained in the microhardness mean value [35]. Similarly, in the case of AA-5754, the increase was from 89.1 to $100.0 \mathrm{HV}$ (that is, of $12.2 \%$ ) [36]. 


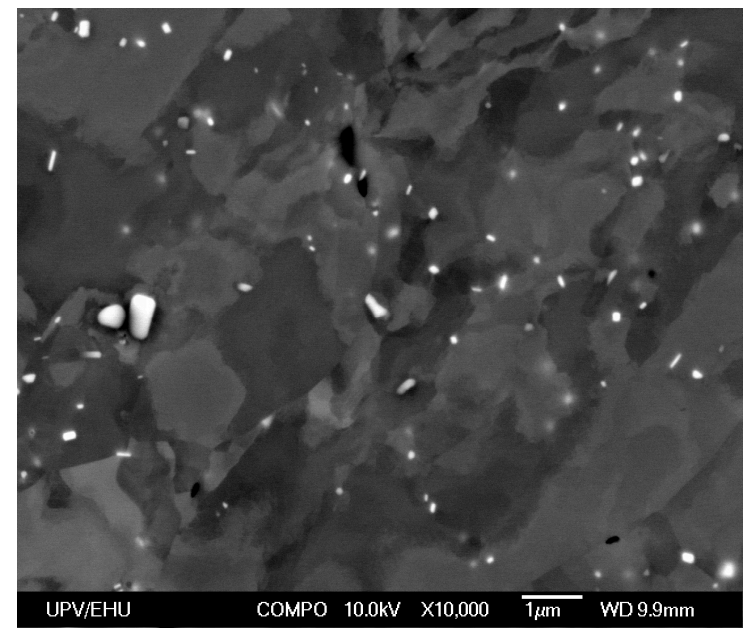

(a)

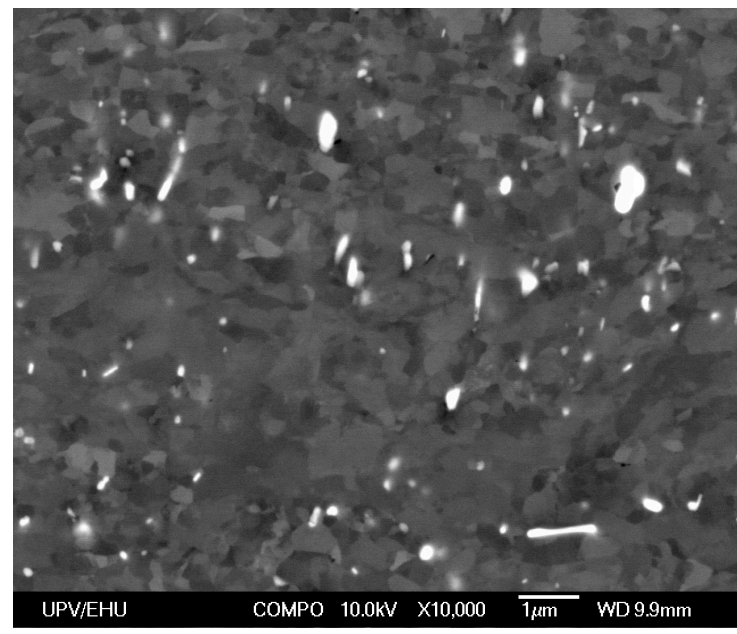

(b)

Figure 4. Scanning electron microscopy (SEM) micrographs of different isothermally-forged AA-5083 states: (a) AA-5083 at N0 (annealed); (b) AA-5083 at N2 (equal channel angular pressing (ECAP)-processed). Taken from the research work by León et al. [23].

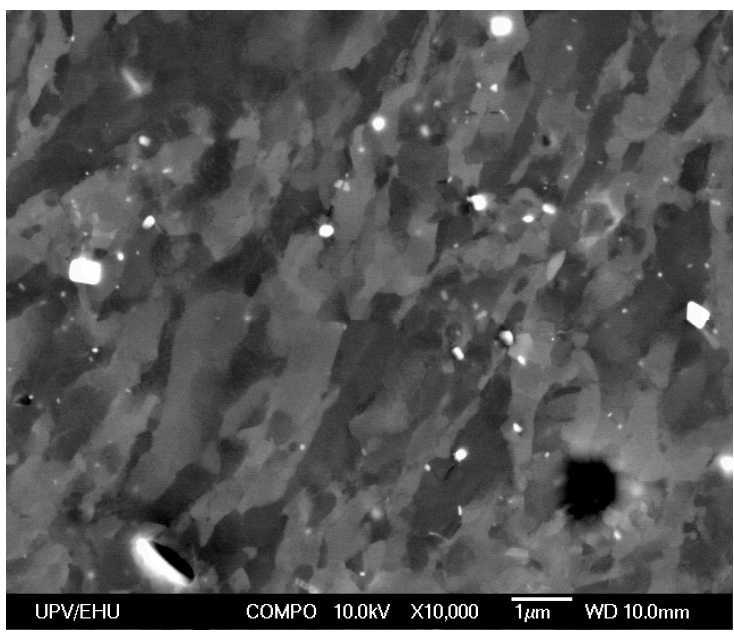

(a)

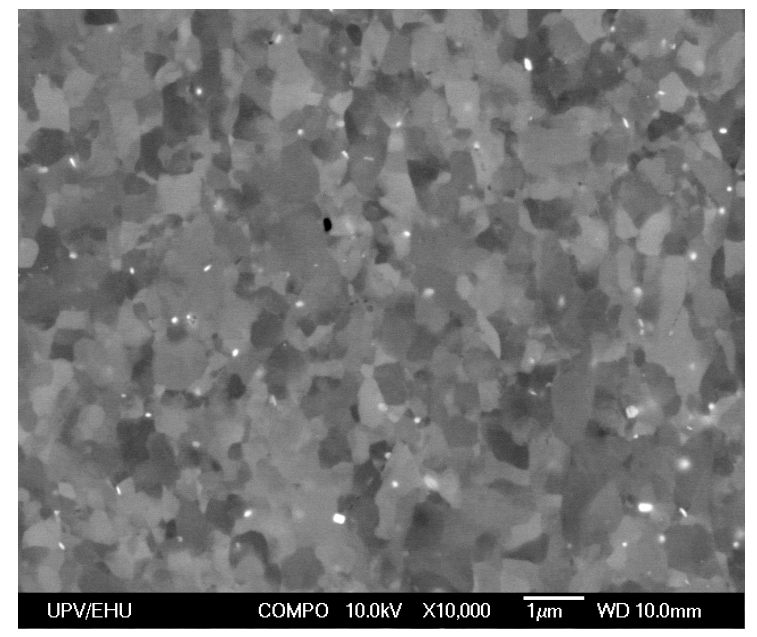

(b)

Figure 5. SEM micrographs of different isothermally-forged AA-5754 states: (a) AA-5754 at N0 (annealed); (b) AA-5754 at N2 (ECAP-processed). Taken from the research work by León et al. [23].

Finally, the forged material was again machined in order to obtain the test disks. In addition to this, disks from non-ECAP-processed material were also manufactured, where these were named as AA-5083-F380 and AA-5754-F380. Cylindrical billets from AA-5083 and AA-5754 were machined with a diameter of $18 \mathrm{~mm}$ and a length of $36 \mathrm{~mm}$, and then they were isothermally forged at a temperature of $380^{\circ} \mathrm{C}$, which is inside the temperature range generally used for these aluminium alloys [37]. Finally, the forged material was again machined in order to obtain the test disks shown in Figure 3.

In order to evaluate the improvement in mechanical properties which may be attributed to the ECAP process and to the isothermal forging one, disks of AA-5754 and AA-5083 were also manufactured from isothermal forging at temperatures of 150 and $200{ }^{\circ} \mathrm{C}$, respectively. These material states were named as AA-5754-N0 and AA-5083-N0. The difference between AA-5754-N0 and AA-5083-N0 states and AA-5754-N2 and AA-5083-N2 states is that the former were forged at the same temperature as the latter but they were not ECAP-processed. In addition to this, disks from material in an annealed state were manufactured, which were named as AA-5754-O and AA-5083-O. 
All the disks are first tested under a load of $0.6 \mathrm{kN}$, which is equivalent to a mean value of stress of $18 \mathrm{MPa}$, and at a rotational speed of $200 \mathrm{rpm}$. This load value is selected to perform accelerated wear tests. An SAE 5W30 oil (Shell, The Hague, Netherlands) was used as a lubricant for all the cams tested, using new oil for each test so that all wear tests were carried out under the same conditions. The friction couple was composed of AA5083 and hardened steel. In order to evaluate the wear behaviour, the disks were weighed at the beginning, at 10,000 revolutions, at 50,000 revolutions and at 100,000 revolutions and thus the volume loss for each stage $\left(V_{\text {init }}-V_{f}\right)$ was calculated. In order to do this, each disk was weighed three times and the mean value was taken. The precision weighing scale used (Mettler Toledo XS104; Mettler-Toledo, Columbus, OH, USA) had an uncertainty value of $\pm\left(0.04+2 \times 10^{-7} \times\right.$ weight $) \mathrm{mg}$.

\section{FEM Simulations}

The forging process of the disks consisted of an isothermal compression between plane-shape dies at a temperature of $200{ }^{\circ} \mathrm{C}$, as shown in Figure 6a. This process was simulated by finite element modelling with the MSC Marc ${ }^{\circledR}$ Mentat ${ }^{\circledR} 2018$ (MSC Software Corporation, Hamburg, Germany) and MSC Simufact Forming 15.0 (MSC Software Corporation, Hamburg, Germany). In order to generate the model, two rigid dies were used as well as a deformable cylindrical billet with a diameter of $18 \mathrm{~mm}$ and a height of $36 \mathrm{~mm}$. The contact simulated between the three bodies was of node-to-segment type, where the friction coefficient was Shear's type and had a value of 0.3 . As was previously mentioned, the isothermal forging was carried out at a temperature of $200{ }^{\circ} \mathrm{C}$ and taking the convection with the environment into account, which is considered to be at a room temperature of $25^{\circ} \mathrm{C}$. The compression stroke was $29 \mathrm{~mm}$, which means that the final height value is $7 \mathrm{~mm}$.

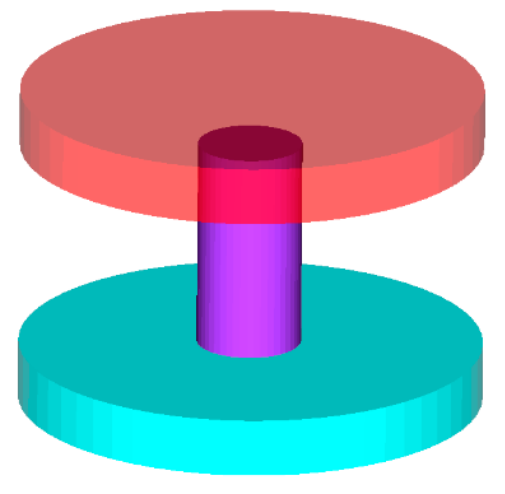

(a) Isothermal compression model

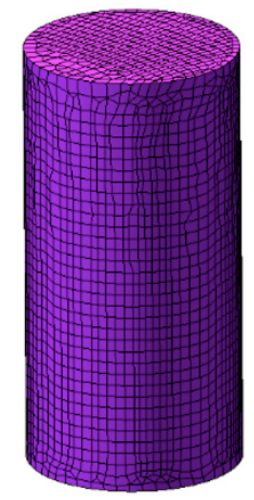

(b) Billet meshing

Figure 6. Simulation of the manufacturing of disks by isothermal compression, where the initial cylindrical billet (in purple colour) has a diameter of $18 \mathrm{~mm}$ and a length of $36 \mathrm{~mm}$.

In order to mesh the deformable billet, an element size between 0.25 and $1 \mathrm{~mm}$ was used along with a coarsening factor of 2 . Under these conditions, a total of 16,882 elements of Overlay-Hex type were obtained with eight integration nodes, as Figure $6 \mathrm{~b}$ shows. These meshing conditions were also assigned to the re-meshing process, which was carried out during the simulation every 25 increments.

The deformable material was assigned the flow rule proposed in research by León et al. [23], which is shown in Equation (1) where the behaviour of several aluminium alloys is modelled at different temperature values and with an initial state which consists of an annealing process and a subsequent ECAP process.

$$
\sigma_{N}=\sigma_{2}+\left(a+\frac{b \cdot \varepsilon^{n}}{c+\varepsilon^{2}}\right) \cdot e^{-d \cdot \varepsilon}
$$

The flow rule employed in this present study has six constitutive parameters: $\sigma_{2}, a, b, c, d$ and $n$. The values of these depend on the case under consideration: aluminium alloy, deformation state 
and forging temperature [23]. In the case of AA-5083, as the ECAP-processed material was forged at $200{ }^{\circ} \mathrm{C}$, the selected values for the constitutive parameters are as follows: $a=-27.98, b=58.86, c=5.09$ $\times 10^{-5}, d=2.50, n=2.00$ and $\sigma_{2}=314.38$, whereas in the case of AA-5754, where the ECAP-processed material was forged at $150{ }^{\circ} \mathrm{C}$, the values are as follows: $a=-53.94, b=67.81, c=7.18 \times 10^{-1}, d=1.30$, $n=0.20$ and $\sigma_{2}=331.96$.

Figure 7a-d show the AA-5083 plastic strain distribution inside the billet throughout the isothermal compression process between plane-shape dies. As can be observed in the longitudinal sections from the billet shown in Figure $7 c, d$, the highest strain value takes place at the inner part of the billet. Specifically, at the central zone (2.382), whereas the zones with the lowest values take place at the centres of the faces (0.447). In addition, it may be observed that the strain distribution along the side zone is completely homogeneous. The outer zone in the final machined disk, where the contact between the follower and the disk takes place in the experimental test (highlighted with a red rectangle in Figure 7d), has a plastic strain value of around 1.6. With regard to the plastic strain results obtained for AA-5754, these turn out to be very similar.

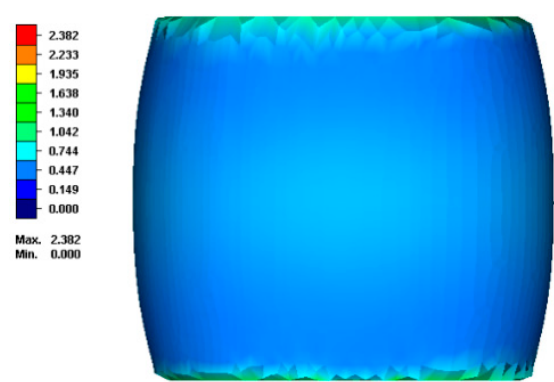

(a) Compression at 50\%

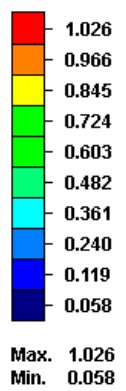

(c) Longitudinal section of the compression process at $50 \%$.
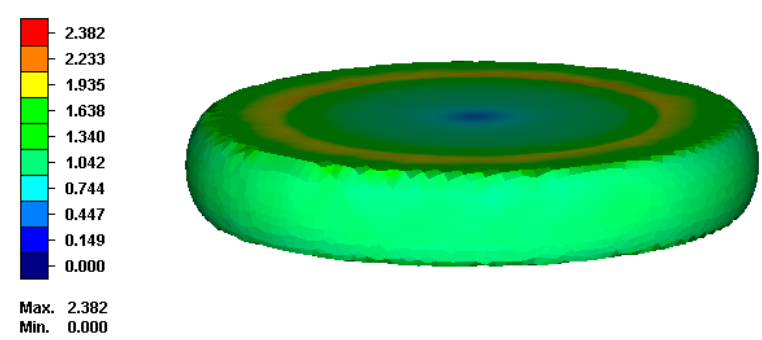

(b) Compression at $100 \%$
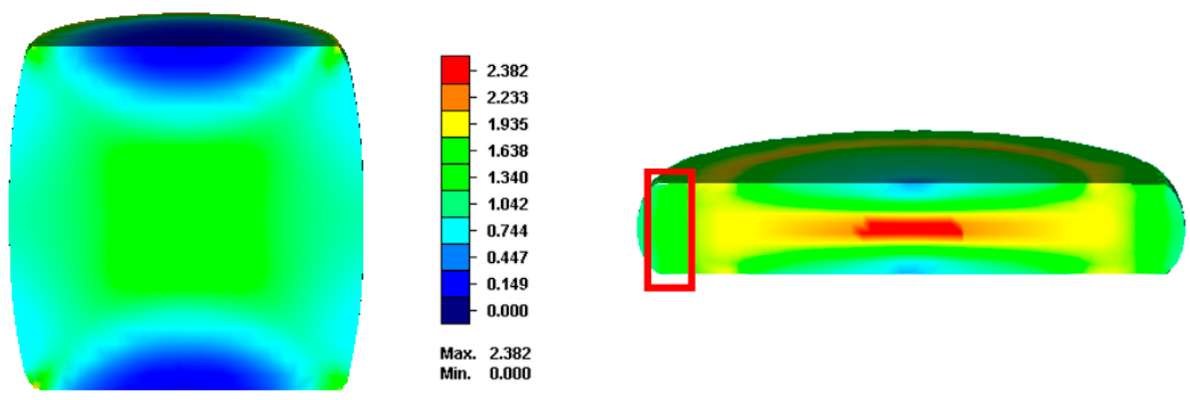

(d) Longitudinal section of the compression process at $100 \%$, where the contact zone between the follower and the disk has been highlighted with a red rectangle

Figure 7. Plastic strain distribution during the manufacturing process of disks for AA-5083.

The study on the plastic strain distribution throughout the isothermal compression for the manufacturing of the disks has been completed with its corresponding damage analysis. Figure 8a-d show the damage distribution inside the billet (outer and inner zones) along the compression process. Thus, it may be observed that the highest damage value takes place at the outer side zone. Moreover, the lowest damage value occurs at the inner part of the billet and, as a consequence, if cracks or defects appear, these will be visible to the naked eye. The maximum damage value achieved in the billet turns out to be 0.595 , according to Crockroft-Latham's criterion. Taking the study by Luri et al. [38] into consideration (which deals with how to determine absolute critical damage for ECAP-processed AA-5754 and AA-5083), this value is found to be below the critical damage and thus, no cracks would appear at the outer surface of the disks during the isothermal forging process. Furthermore, the zone 
where the contact between the follower and the disk takes place in the experimental test (highlighted with a red rectangle in Figure 8d) has a damage value of around 0.2.

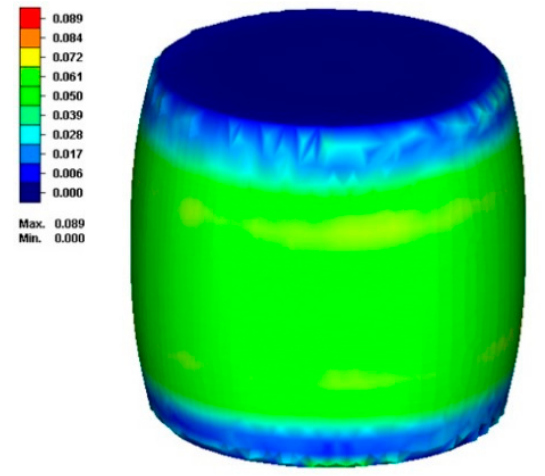

(a) Compression at $50 \%$

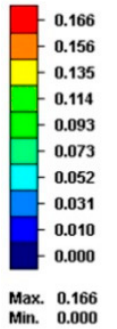

(c) Longitudinal section of the compression process at $50 \%$

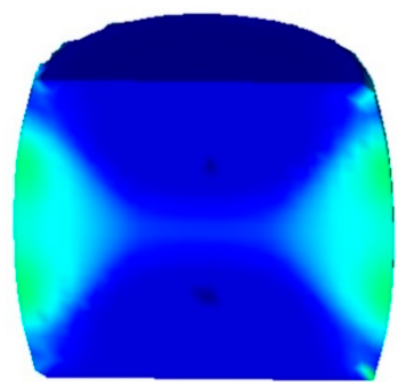

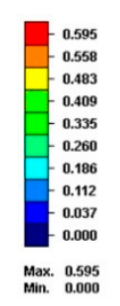

(b) Compression at $100 \%$
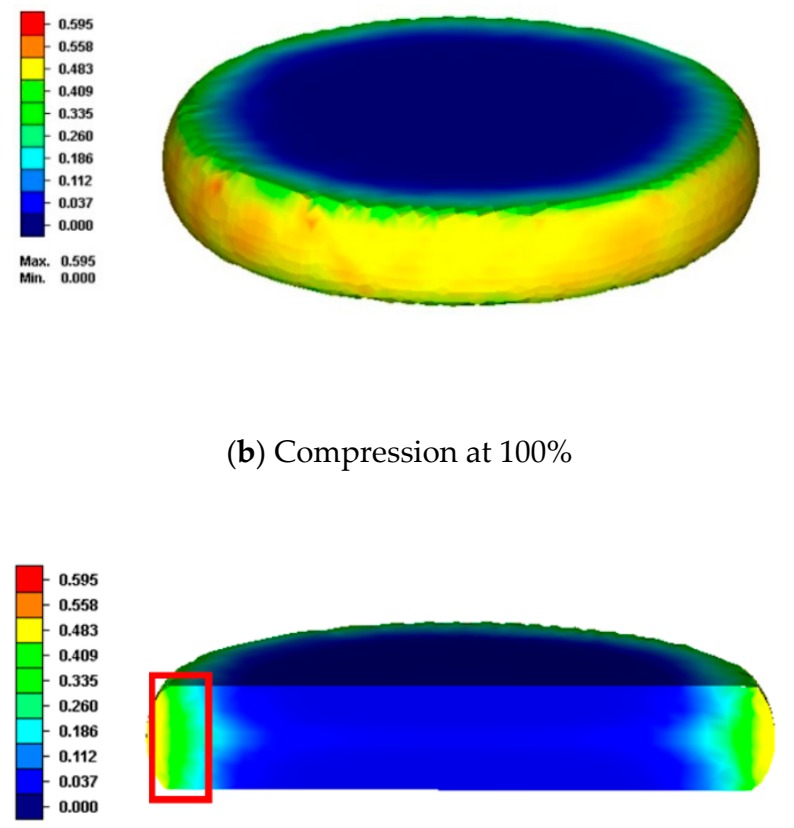

Max. 0.595
Min. 0.000

(d) Longitudinal section of the compression process at $100 \%$, where the contact zone between the follower and the disk has been highlighted with a red rectangle

Figure 8. Damage distribution during the manufacturing process of disks.

A differential mesh was carried out for the ring and the follower, where the elements with the smallest size were introduced in the contact zone between both parts, as can be observed in Figure 9 .

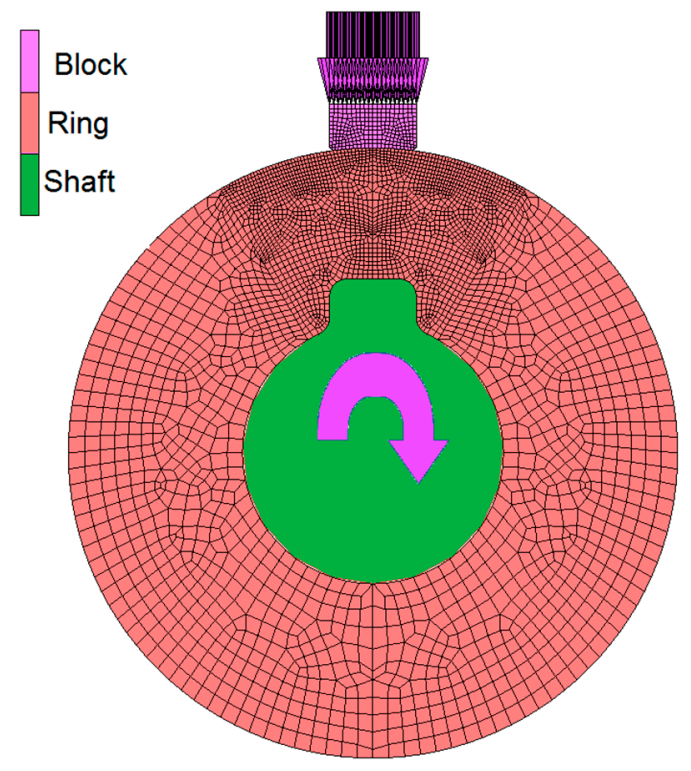

Figure 9. Mesh for the block-on-ring system. 
Two deformable contact bodies were used for both the ring and the block and one rigid contact body was used for the shaft. The pin was subjected to a force value of $1 \mathrm{kN}$ and the shaft to a rotational speed of $60 \mathrm{rpm}$. Values of $210 \mathrm{GPa}$ and $70 \mathrm{GPa}$ were considered for the Young's modulus of steel and aluminium, respectively. The plane stress hypothesis was used for the FEM simulations. In addition, quad4 elements were employed with a differential mesh where the smallest elements were considered at the contact zone between the ring and the block, as was previously mentioned. With this, there are always at least 21 nodes in contact between both bodies with an edge size value of $0.21 \mathrm{~mm}$. Figure 10 shows the normal contact force and the contact pressure obtained in the FEM simulations.

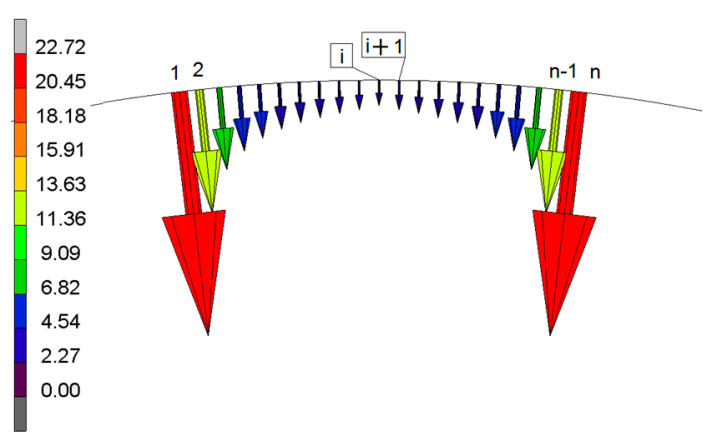

(a)

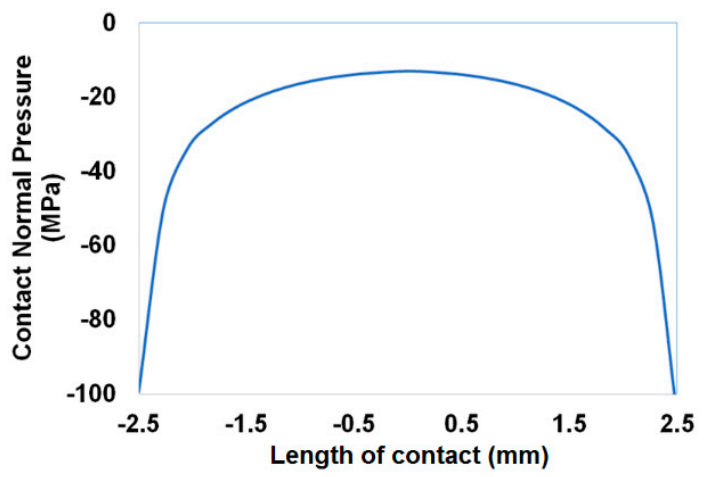

(b)

Figure 10. Normal contact force on the pin with a value of $1 \mathrm{kN}(\mathbf{a})$ and normal contact pressure (b) obtained in the FEM simulations.

If contact pressure values are known and taking Equations (2) and (3) (based on Archard's wear model) into consideration $[39,40]$, it is possible to determine wear and wear rate.

$$
\begin{gathered}
\text { wear rate }=k \cdot \frac{(\text { Contact Pressure }) \cdot\left(V_{\text {sliding }}\right)}{H v} \\
\text { wear }=k \cdot \frac{(\text { Contact pressure }) \cdot\left(L_{\text {sliding }}\right)}{H v}
\end{gathered}
$$

where $\mathrm{Hv}$ is the surface hardness expressed in Vickers hardness, $V_{\text {sliding }}$ is the relative sliding velocity, $L_{\text {sliding }}$ is the sliding length and $k$ is the adimensional wear coefficient.

The wear value per revolution at each point from the surface occurs along the sliding from point 1 to point $n$, as can be observed in Figure 10. In the simulation performed, there are 21 nodes in contact between the ring and the block. Taking Equation (3) into account and for a point at the disk surface which moves from $i$ to $i+1$, the wear value may be calculated, as Equation (4) shows.

$$
\text { wear }(\text { i to } i+1)=\frac{k \cdot\left(L_{i} \text { to } i+1\right)}{H v} \cdot\left(\text { Contact } \text { Pressure }_{i}\right)
$$

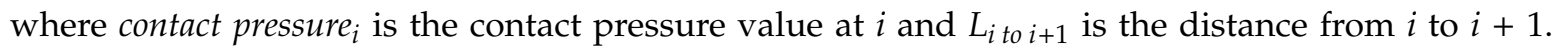
The wear value at one point on the disk surface and during one revolution may be obtained as the incremental sum of wear values, as is shown in Equation (5).

$$
\frac{\text { wear }}{\text { rev }}=\frac{k}{H v} \cdot \sum_{i=1}^{n}\left(\text { Contact Pressure }_{i}\right) \cdot\left(L_{i} \text { to } i+1\right)
$$


As the distance value for $L_{i}$ to $i+1$ in the FEM simulation is $0.21 \mathrm{~mm}$ for all the 21 points and the contact pressure for all of these is known when the pin undergoes a force value of $1 \mathrm{kN}$ (see Figure 10), Equation (5) may be transformed into Equation (6).

$$
\frac{\text { wear }}{\text { rev }}=167.33 \cdot \frac{k}{H v}
$$

Due to the design of the contact pin (its apparent contact area value is assumed to be constant), contact pressure is linearly dependent on force and thus the wear value as a function of the applied force may be deduced from Equation (6), as Equation (7) shows.

$$
\frac{\text { wear }}{\text { rev }}=167.33 \cdot \frac{k}{H v} \cdot F_{v}
$$

For a test where rev is the total number of revolutions for the test, $k$ is the adimensional wear coefficient, $\mathrm{Hv}$ is the surface hardness and $F_{v}$ is the vertical force applied to the pin expressed in $\mathrm{kN}$, the wear value for a set of ring-block as that shown in Figure 2 may be calculated as Equation (8) shows.

$$
\text { wear }=167.33 \cdot(\mathrm{rev}) \cdot \frac{k}{\mathrm{Hv}} \cdot F_{v}
$$

Figure 11 shows the disk after the wear test along with its corresponding final volume loss. If the disk volume values before the test $\left(V_{\text {init }}\right)$ and after the test $\left(V_{f}\right)$ are known, it is possible to determine the wear value, as Equation (9) shows.

$$
\frac{V_{\text {init }}-V_{f}}{\Pi \cdot D \cdot w}=\text { wear }
$$

where $V_{\text {init }}$ is the initial volume, $V_{f}$ is the final volume, $w$ is the disk thickness and $D$ is the disk diameter. If Equation (9) is substituted into Equation (8), Equation (10) is obtained, from which the wear dimensional coefficient $(K)$ may be calculated for the case of an experimental test.

$$
K=\frac{k}{H v}=\frac{\left(V_{\text {init }}-V_{f}\right)}{167.33 \cdot F_{v} \cdot \Pi \cdot D \cdot w \cdot(r e v)}\left(M P a^{-1}\right)
$$

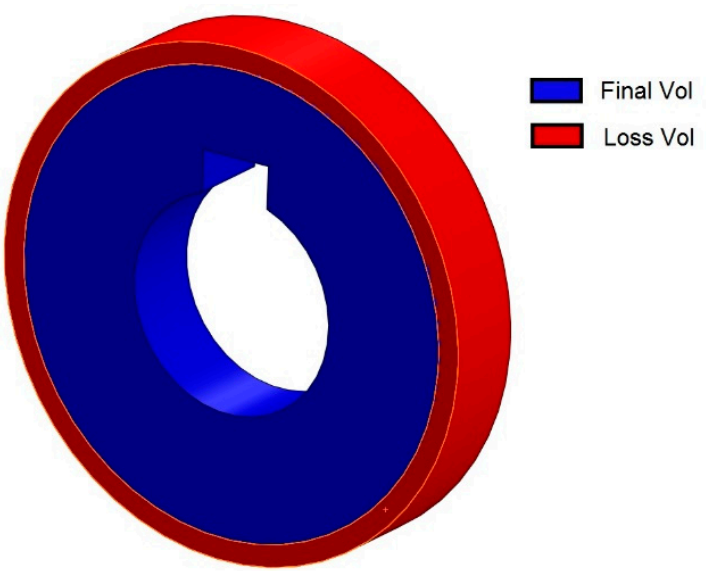

(a)

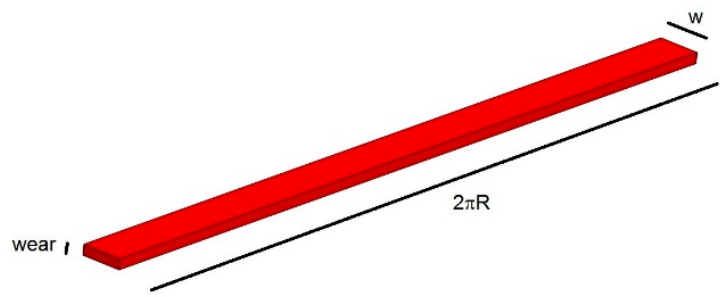

(b)

Figure 11. Disk after the wear experimental test (a) and final volume loss (b). 


\section{Results and Discussion}

The wear study was carried out for the disks made of aluminium alloys AA-5083 and AA-5754. As previously mentioned, for each of the two aluminium alloys, four different initial states were taken into consideration. Once the eight disks (four per alloy) were manufactured, the wear tests were performed in a piece of specifically designed equipment [22]. Figure 12 shows the eight manufactured disks after having undergone the wear tests.
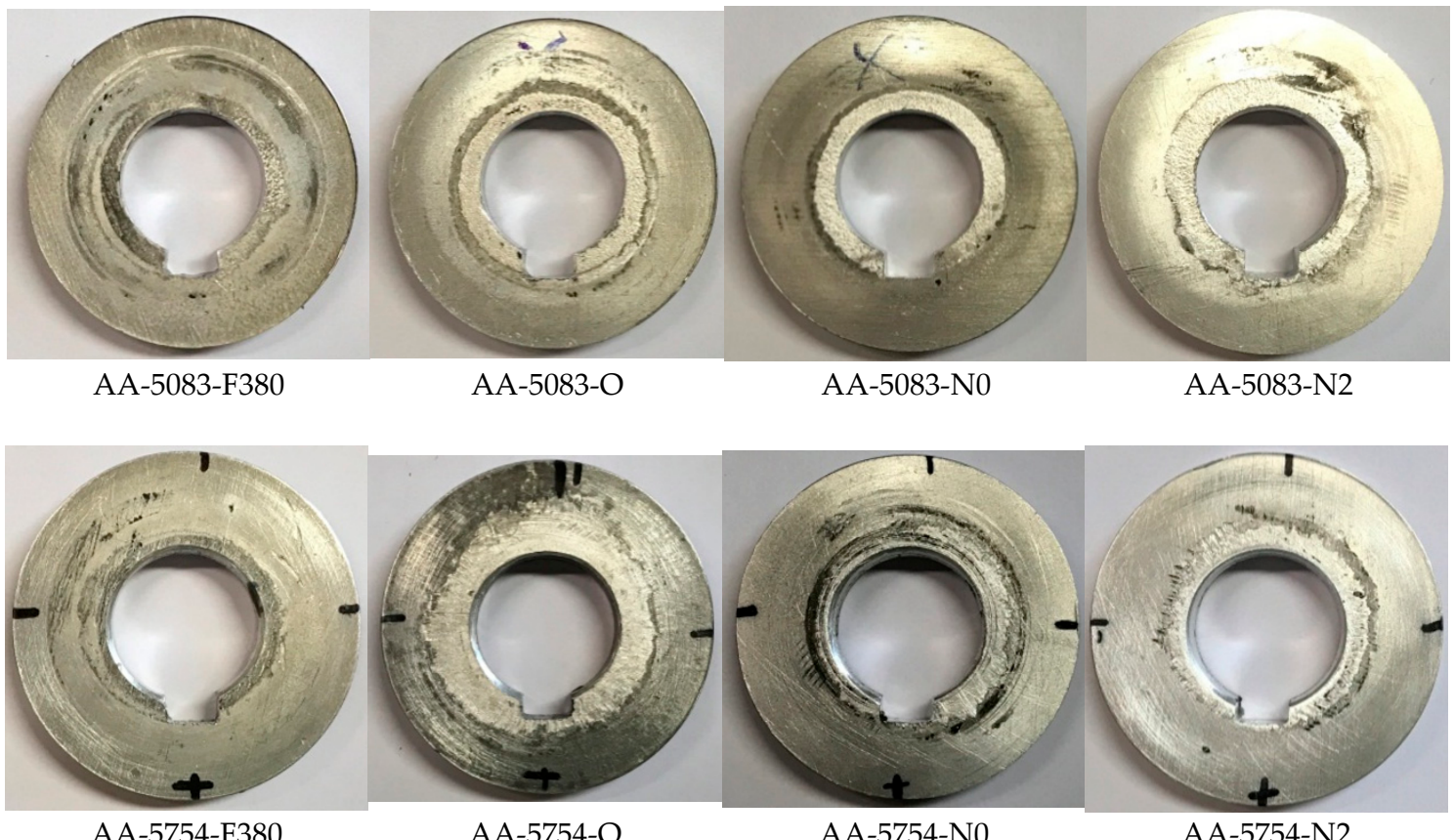

Figure 12. Disks after the wear tests.

The next step was to cut the disks in such a way that these may be analysed by scanning electron microscopy (SEM) in order to study the different surface finishes. Given that the disks had a circular shape, these were cut into samples as is shown in Figure 13. Over these cut samples, SEM images were taken at different magnifications.
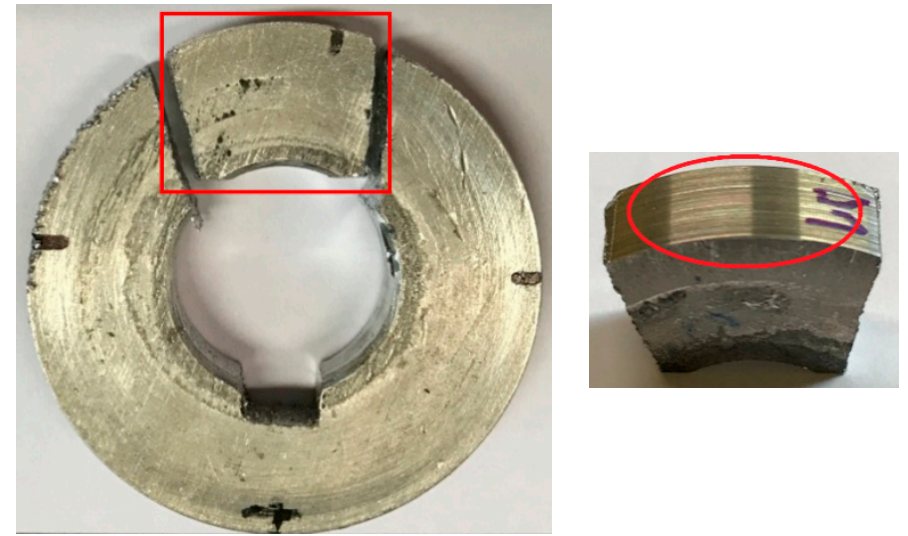

Figure 13. Cut disk and study zone highlighted in red.

Prior to the SEM analysis, all the samples were cleaned with acetone in order to remove the remaining lubricant stains due to the wear tests. A JEOL 6400 scanning electron microscope (JEOL, Tokyo, Japan) was used to take the SEM micrographs, where its two most important working parameters 
were as follows: acceleration voltage of $20 \mathrm{kV}$ and beam current of around $0.1 \mathrm{nA}$. In addition, secondary electrons were used to obtain the micrographs from the cut samples.

Some of the AA-5083 SEM micrographs taken are shown below. Figure 14 shows the SEM micrographs for the thus-called AA-5083-F380 disk. SEM micrographs were taken at different magnifications: $\times 50, \times 200, \times 500$ and $\times 1000$. It may be observed that grooves are perfectly aligned and these possess a quite homogeneous width value. Particles of removed material are also observed. In addition, it may be observed that grooves have a certain value of depth given the contrast which is seen in the SEM micrograph taken at $\times 1000$.
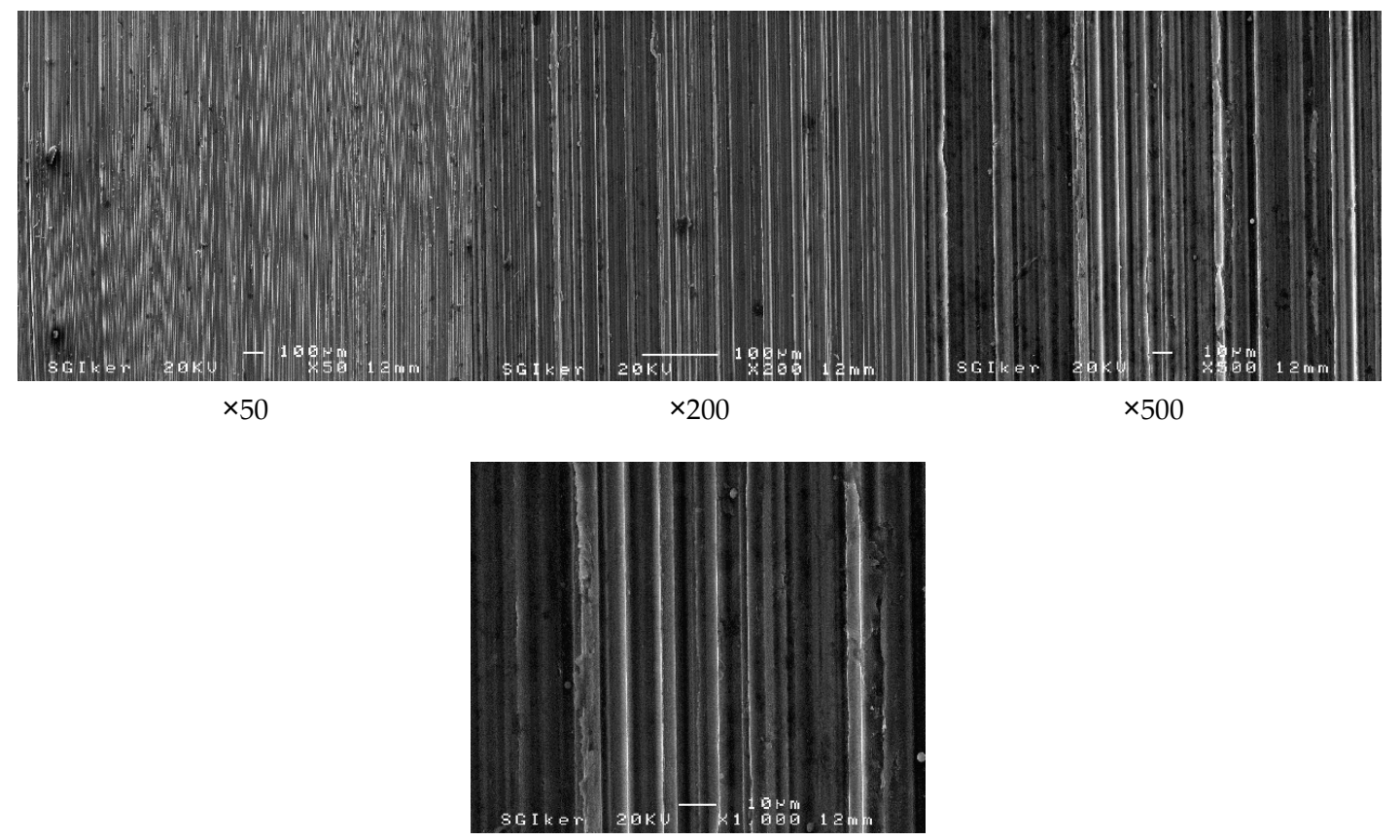

$\times 1000$

Figure 14. AA-5083-F380 disk.

Figure 15 shows the SEM micrographs for the AA-5083-O disk. SEM micrographs were taken at three different magnifications: $\times 50, \times 200$ and $\times 1000$. The results obtained in this case are similar to those obtained in the case of the AA-5083-F380 state. In addition, there is a little more of removed material in this case due to the fact that the homogenization annealing subsequent to the disk manufacturing has decreased the material hardness.

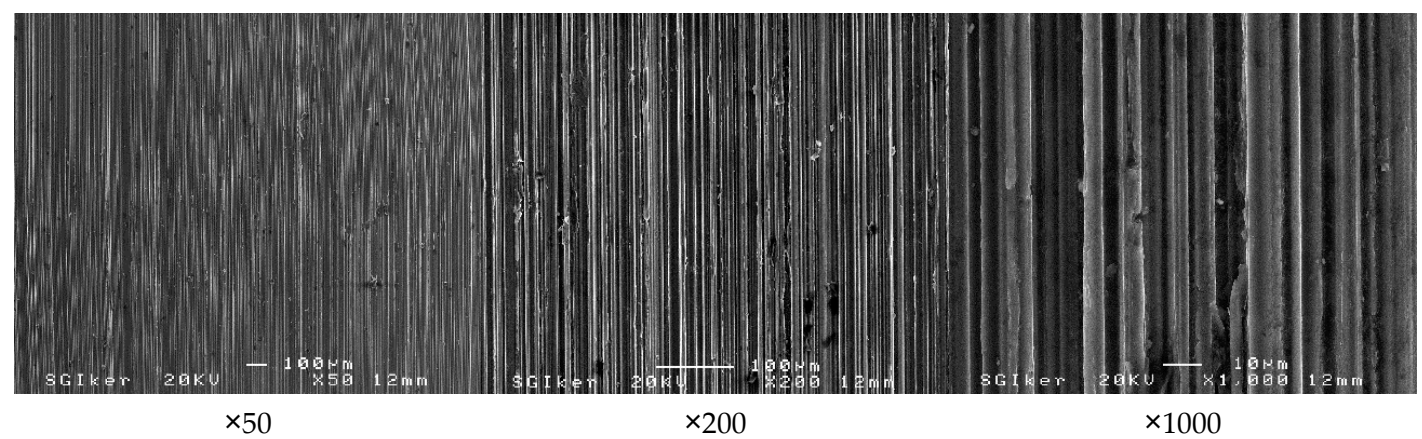

Figure 15. AA-5083-O disk.

Figure 16 shows the SEM micrographs for the AA-5083-N0 disk. SEM images were taken at different magnifications of $\times 50, \times 200$ and $\times 1000$. In comparison to the two previous states, there is less amount of removed material in this case and the groove width remains the same. 


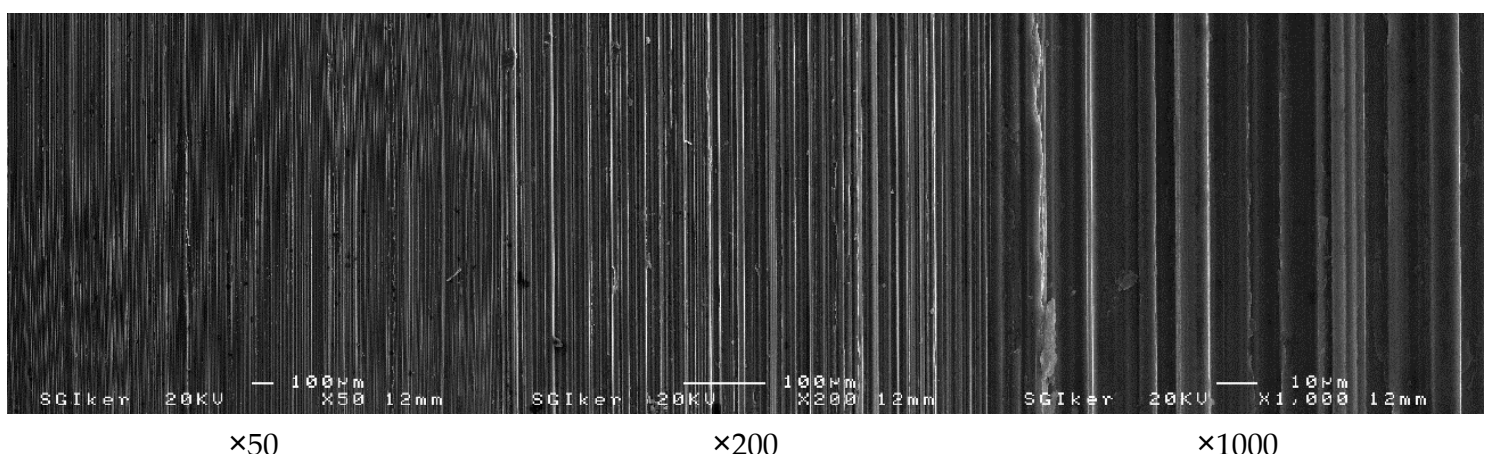

Figure 16. AA-5083-N0 disk.

Finally, Figure 17 shows the SEM images for the AA-5083-N2 disk. SEM images were taken at three different magnifications of $\times 50, \times 200$ and $\times 1000$. It may be clearly seen that the amount of removed material is the lowest in this case and in addition, the groove structure remains the same in terms of alignment and width. Making a comparison between the four cases under consideration for AA5083, it may be concluded that grooves have a similar width value in all cases. The hardest material, which turns out to be AA-5083-N2, clearly shows the lowest amount of removed material and thus this study case leads to the one with the highest mechanical strength.

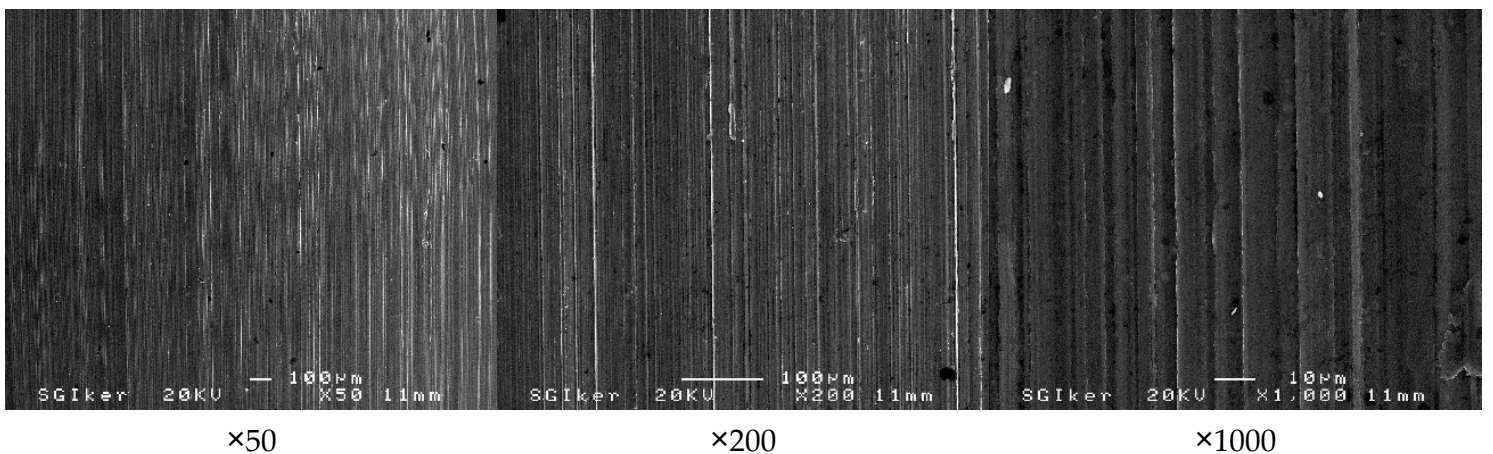

Figure 17. AA-5083-N2 disk.

The results obtained for the disks manufactured from AA5754 are shown below. Figure 18 shows the SEM micrographs for the AA-5754-F380 state. The SEM images were taken at $\times 50, \times 200$ and $\times 1000$. It may be clearly seen that the amount of removed material in this case is quite high and that the groove width is scantily homogenous. In addition, it may be observed that at the zones with the highest wear values, the groove depth is practically negligible.

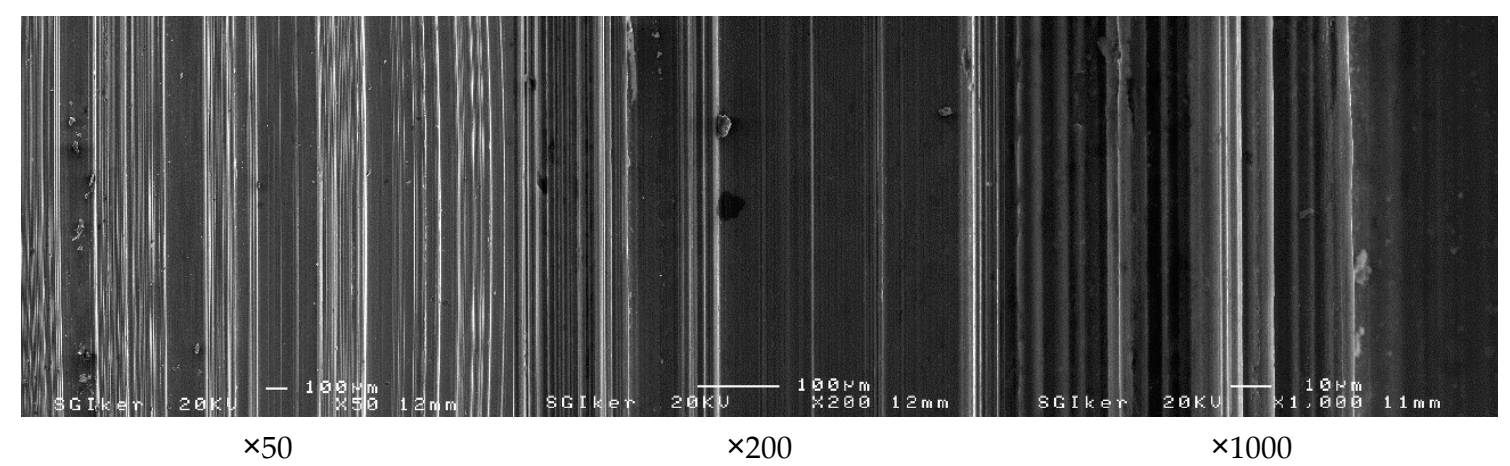

Figure 18. AA-5754-F380 disk. 
Figure 19 shows the SEM micrographs for the AA-5754-O disk. SEM micrographs were taken at three different magnifications of $\times 50, \times 200$ and $\times 1000$. It may be clearly seen in this case that there is a certain amount of removed material but less than in the previous case. The groove width is kept quite homogeneous and there is a certain value of depth in the generated grooves.

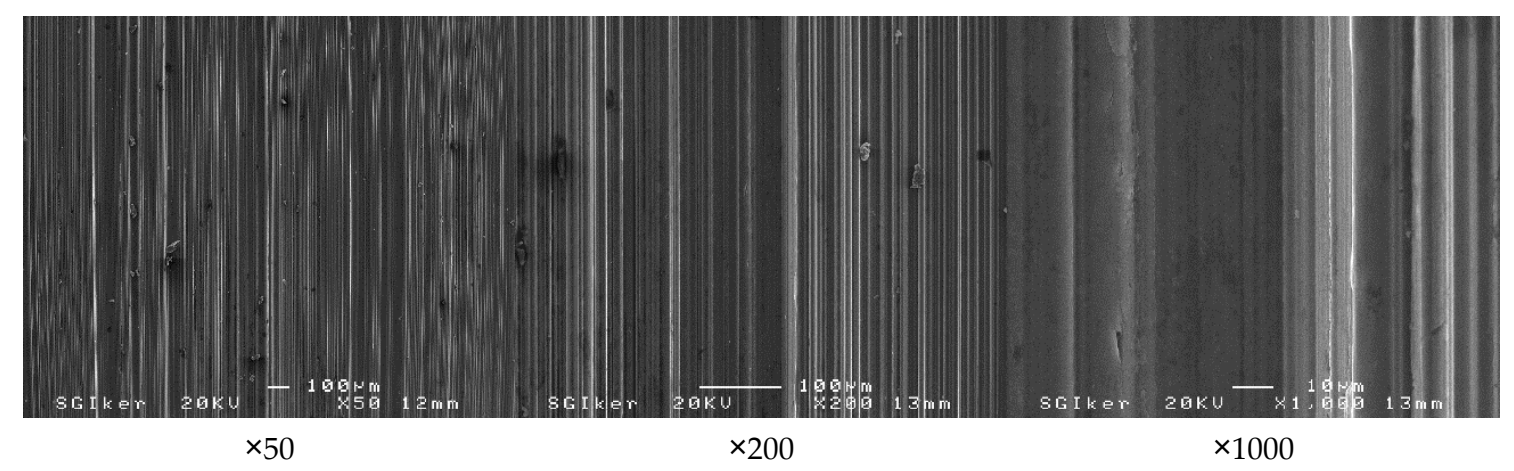

Figure 19. AA-5754-O disk.

Figure 20 shows the SEM micrographs for the AA-5754-N0 state, where these were taken at $\times 50, \times 200$ and $\times 1000$. It may be seen in this case that there exists a structure of homogeneous and aligned grooves but with a much smaller width value than in the two previously mentioned cases. From the SEM image taken at $\times 1000$, it may be pointed out that grooves have little width and low depth. In addition to this, there is practically no removed material.

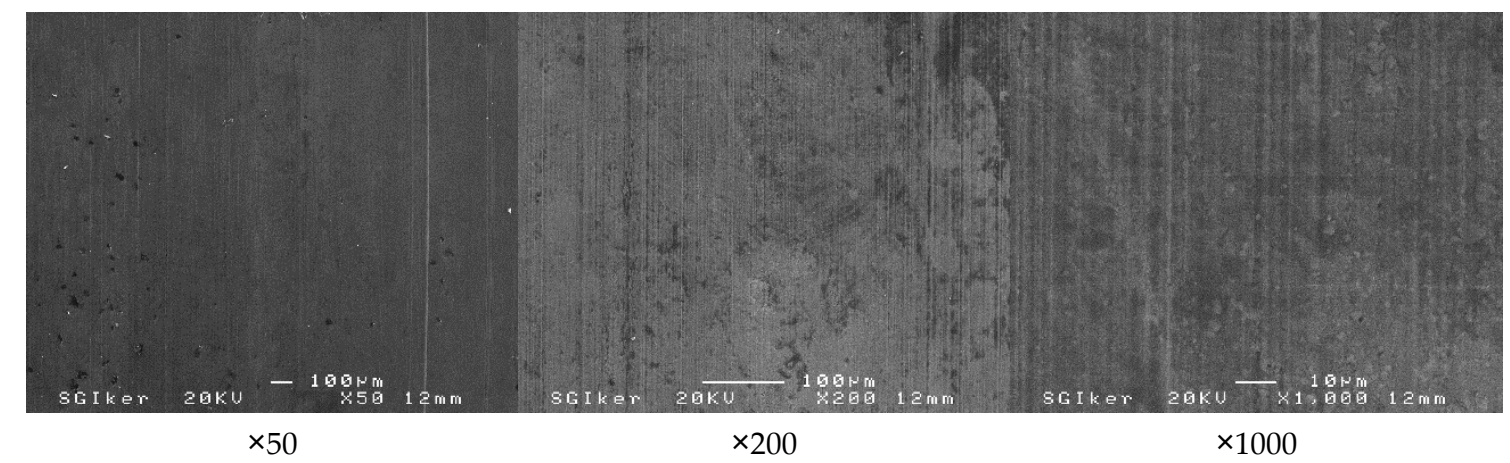

Figure 20. AA-5754-N0 disk.

Finally, Figure 21 shows the SEM images for the AA-5754-N2 disk. A first SEM image was taken at $\times 20$ as there were two clearly different zones in terms of the type of wear undergone.

The central zone of the sample shows a much higher wear value in relation to the side zones. Thus, each of the two different zones was studied individually. For each zone, SEM micrographs were taken at three different magnifications: $\times 50, \times 200$ and $\times 1000$. At the central zone, severe wear may be observed, thus provoking a very high amount of removed material. As a consequence, there are some deeply marked grooves which are not equally distributed and with a big width value between them, but at the same time there are some very fine grooves which can hardly be seen between these initially deeply marked grooves. On the contrary, at the side zones, although there is lower material removal, grooves may be seen with both a homogeneous width and a certain depth value.

As was previously mentioned, in order to evaluate the loss of volume $\left(V_{\text {init }}-V_{f}\right)$ for the different materials and states, each disk was weighed three times at 10,000 (10 K), 50,000 (50 K) and 100,000 $(100 \mathrm{~K})$ revolutions and the mean value was calculated. Table 1 shows the wear value as a function of the number of cycles. 


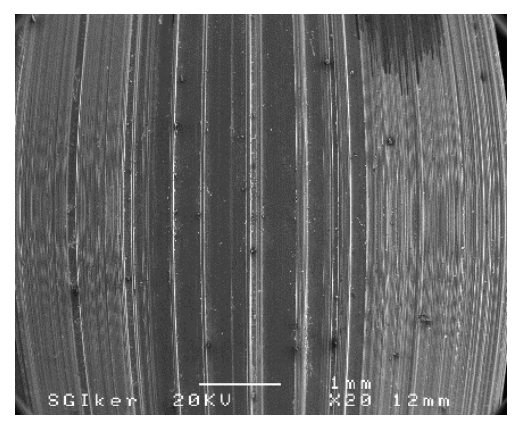

$\times 20$

Central and side zones

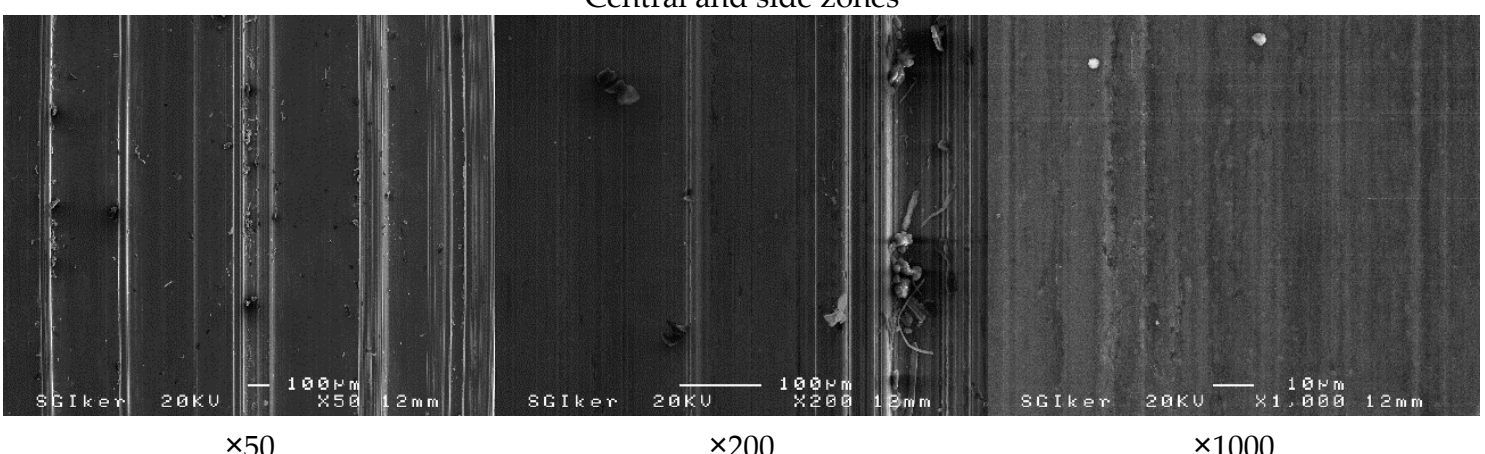

Central zone

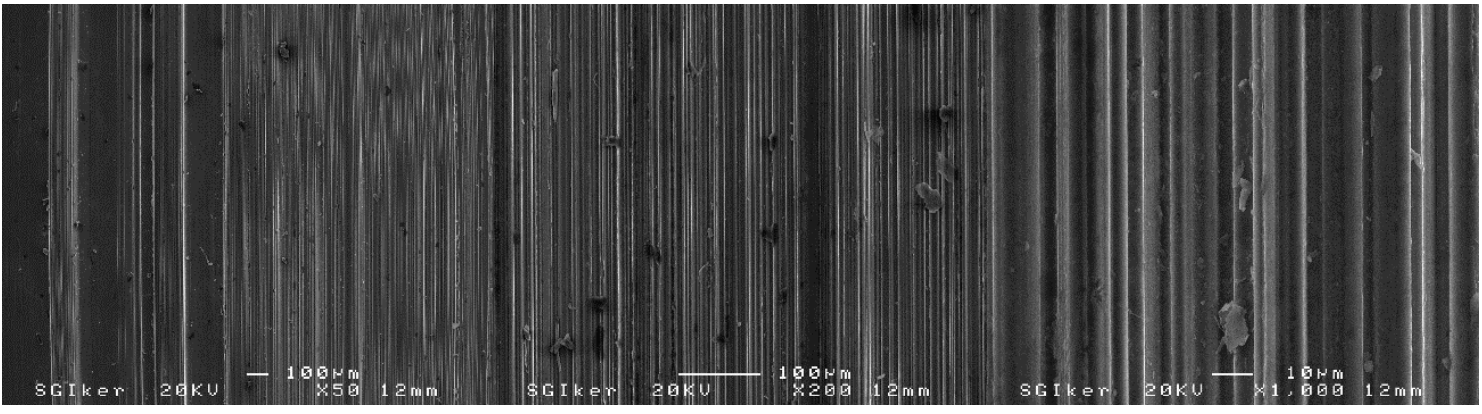

$\times 50$

$\times 200$

$\times 1000$

Side zone

Figure 21. AA-5754-N2 disk.

Table 1. Loss of volume $\left(\mathrm{mm}^{3}\right)$ for the wear tests of AA-5754 and AA-5083 at 10,000, 50,000 and 100,000 revolutions.

\begin{tabular}{|c|c|c|c|}
\hline AA-5083 Study Cases & $\left(V_{\text {init }}-V_{f}\right)(10 \mathrm{~K})$ & $\left(V_{\text {init }}-V_{f}\right)(50 \mathrm{~K})$ & $\left(V_{\text {init }}-V_{f}\right)(100 \mathrm{~K})$ \\
\hline AA-5083-O & 28.0492 & 138.6690 & 275.4647 \\
\hline AA-5083-N0 & 15.8712 & 111.4277 & 222.9314 \\
\hline AA-5083-F380 & 25.8355 & 103.7802 & 223.5967 \\
\hline AA-5083-N2 & 7.3544 & 13.3323 & 18.7893 \\
\hline AA-5754 Study Cases & $\left(V_{\text {init }}-V_{f}\right)(10 \mathrm{~K})$ & $\left(V_{\text {init }}-V_{f}\right)(50 \mathrm{~K})$ & $\left(V_{\text {init }}-V_{f}\right)(100 \mathrm{~K})$ \\
\hline AA-5754-O & 18.8043 & 99.3552 & 167.5492 \\
\hline AA-5754-N0 & 10.7247 & 66.0140 & 155.3450 \\
\hline AA-5754-F380 & 16.1633 & 67.8791 & 159.5661 \\
\hline AA-5754-N2 & 8.3791 & 51.4366 & 107.3791 \\
\hline
\end{tabular}

Figures 22 and 23 show the wear values for the different initial states of AA-5083 and AA-5754, respectively, as a function of the sliding distance. It may be observed in all cases that the wear 
behaviour is approximately linear under the test conditions employed. Furthermore, the nanostructured aluminium alloys (N2) show lower wear values than the cases where the disks are manufactured from the forging process at low temperature (N0), conventional forging process (F380) or with annealed material $(\mathrm{O})$.

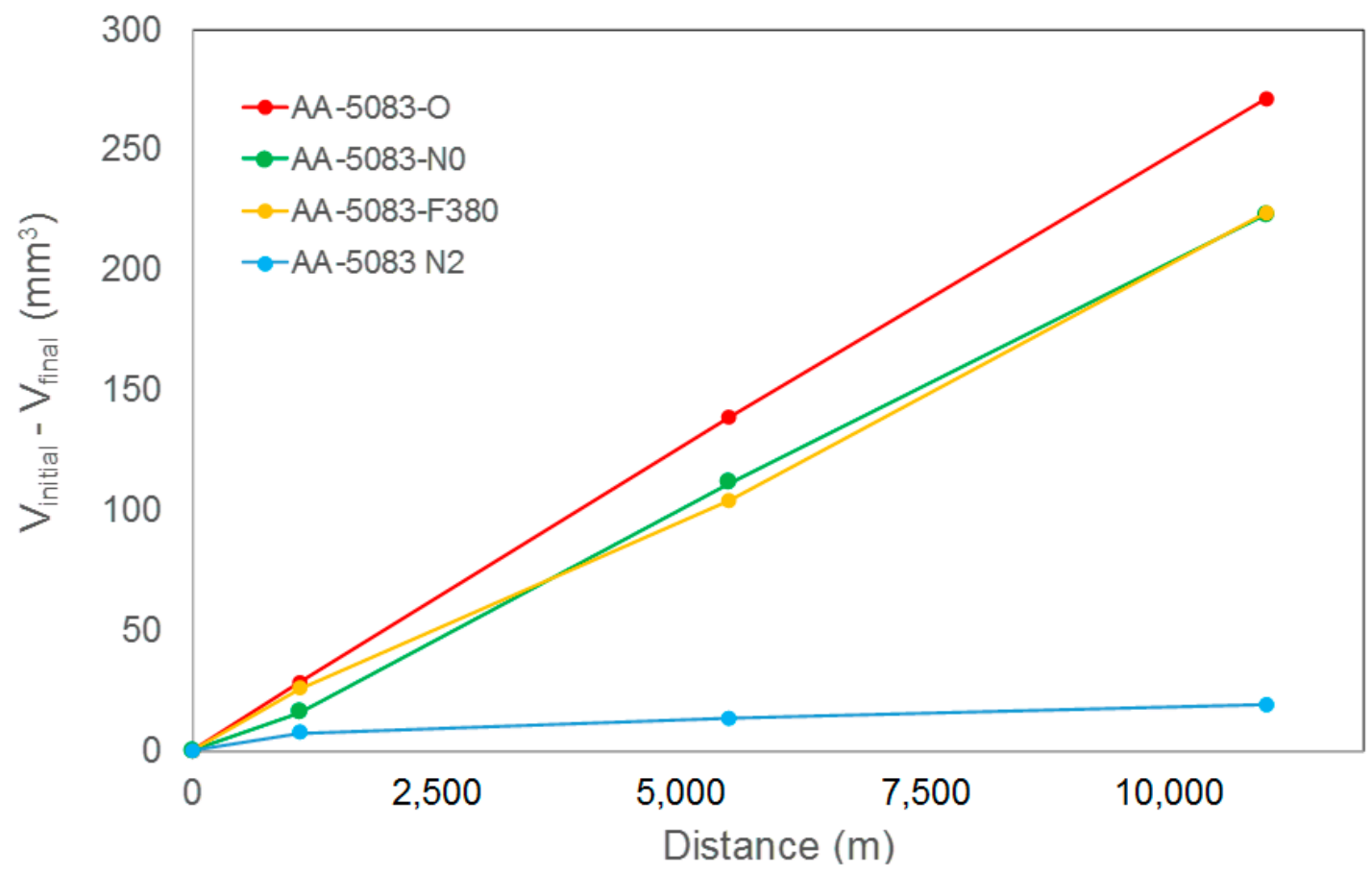

Figure 22. Wear vs. sliding distance for AA-5083.

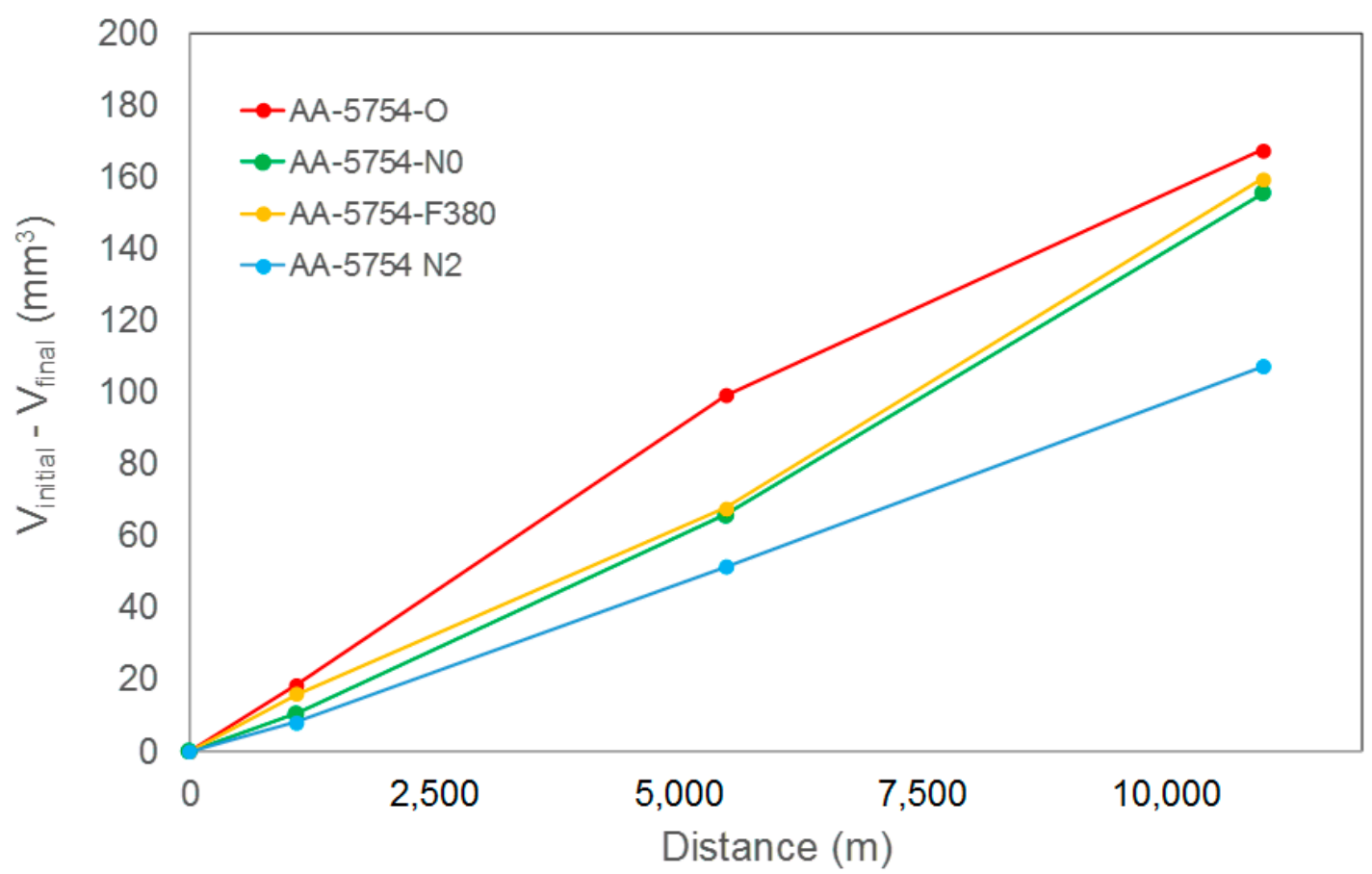

Figure 23. Wear vs. sliding distance for AA-5754.

As can be observed in Figures 22 and 23, the experimental wear behaviour for both AA-5083 and AA-5754, respectively, exhibits a linear tendency in relation to the number of cycles. For all the cases under consideration in this study, it may be observed that the material with the lowest wear value is 
AA-5083-N2, followed by AA-5754-N2 in second place. In addition, it may be pointed out that in the cases of AA-5754 and AA-5083, the non-ECAP-processed aluminium alloys forged at low temperature values (N0) and those conventionally forged (F380) show similar wear values but higher than the ECAP-processed aluminium alloys. The aluminium alloys which have the highest wear values are the annealed ones $(\mathrm{O})$.

As the experimental wear behaviour for both AA-5754 and AA-5083 exhibits a linear tendency in relation to the number of cycles, the hypothesis which was considered in order to determine Equation (10) may be assumed to be correct and thus this equation may be employed in order to calculate the dimensional wear coefficient $(\mathrm{K})$ of the above-mentioned materials, as is shown in Table 2.

Table 2. Dimensional wear coefficients $\left(\mathrm{K}\left(\mathrm{MPa}^{-1}\right)\right)$ for AA-5754 and AA-5083 at 100,000 revolutions.

\begin{tabular}{|c|c|}
\hline AA-5083 Study Cases & $\mathrm{K}\left(\mathrm{MPa}^{-1}\right)(100 \mathrm{~K})$ \\
\hline AA-5083-O & $3.901 \times 10^{-8}$ \\
\hline AA-5083-N0 & $3.121 \times 10^{-8}$ \\
\hline AA-5083-F380 & $3.348 \times 10^{-8}$ \\
\hline AA-5083-N2 & $2.685 \times 10^{-8}$ \\
\hline AA-5754 Study Cases & $\mathrm{K}\left(\mathrm{MPa}^{-1}\right)(100 \mathrm{~K})$ \\
\hline AA-5754-O & $2.371 \times 10^{-8}$ \\
\hline AA-5754-N0 & $2.182 \times 10^{-8}$ \\
\hline AA-5754-F380 & $2.393 \times 10^{-8}$ \\
\hline AA-5754-N2 & $1.474 \times 10^{-8}$ \\
\hline
\end{tabular}

The experimentally obtained wear coefficients were used for the FEM simulations. Wear tests were simulated for each material with a load of $0.6 \mathrm{kN}$ and at $200 \mathrm{rpm}$. Figure 24 shows the wear index per revolution at the surface of the disk from AA-5083-F380.

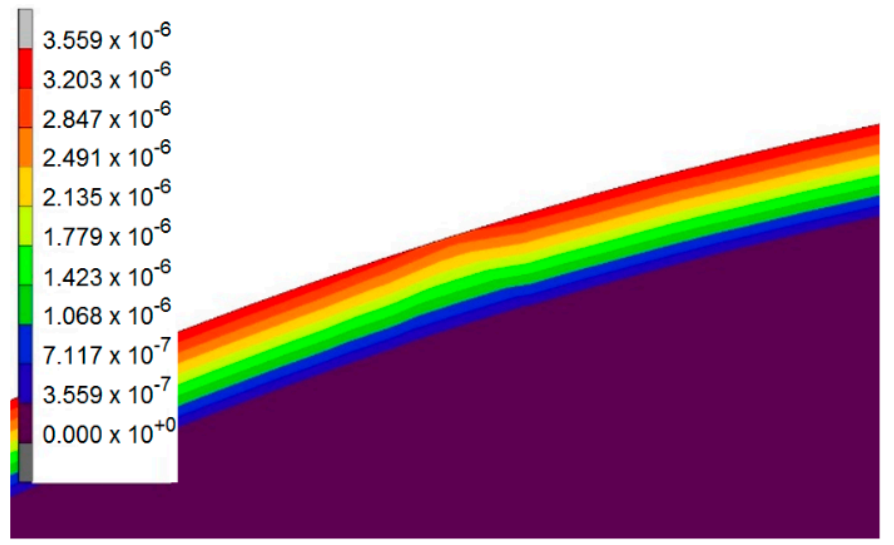

Figure 24. FEM simulation of wear for AA-5083-F380 with a load of $0.6 \mathrm{kN}$ and at $200 \mathrm{rpm}$ (wear index per revolution).

The FEM simulations were performed using the different wear coefficient values, and wear values at 100,000 revolutions were calculated in order to make a comparison with the experimental results. Table 3 shows the results obtained from the simulations and those from the experimental tests along with the difference (expressed in percentage) between them. It may be observed that the maximum difference between FEM results and experimental results is around 5\%. 
Table 3. Wear in terms of volume loss $\left(\mathrm{mm}^{3}\right)$ for FEM simulations and experimental tests at 100,000 revolutions.

\begin{tabular}{|c|c|c|c|}
\hline AA-5083 Study Cases & $\left(V_{\text {init }}-V_{f}\right)(100 \mathrm{~K})$ FEM & $\left(V_{\text {init }}-V_{f}\right)(100 \mathrm{~K})$ EXP & $\%$ Difference \\
\hline AA-5083-O & 273.53 & 271.29 & $0.83 \%$ \\
\hline AA-5083-N0 & 218.90 & 222.93 & $1.81 \%$ \\
\hline AA-5083-F380 & 234.67 & 223.60 & $4.95 \%$ \\
\hline AA-5083-N2 & 18.83 & 18.79 & $0.21 \%$ \\
\hline AA-5754 Study Cases & $\left(V_{\text {init }}-V_{f}\right)(100 \mathrm{~K})$ FEM & $\left(V_{\text {init }}-V_{f}\right)(100 \mathrm{~K})$ EXP & $\%$ Difference \\
\hline AA-5754-O & 166.32 & 167.55 & $0.73 \%$ \\
\hline AA-5754-N0 & 152.93 & 155.35 & $1.56 \%$ \\
\hline AA-5754-F380 & 167.57 & 159.57 & $5.02 \%$ \\
\hline AA-5754-N2 & 103.31 & 107.38 & $3.79 \%$ \\
\hline
\end{tabular}

\section{Conclusions}

The wear behaviour of two previously ECAP-processed aluminium alloys (AA-5754 and AA-5083) is analysed. In order to make a comparison between ECAP-processed and non-ECAP-processed aluminium alloys, several disks made of these alloys are manufactured by isothermal forging from distinct initial states. Moreover, a comparison between forging at low temperature and conventional forging is also carried out. The study cases under consideration in this present research are as follows: forging at low temperature ( 150 and $200{ }^{\circ} \mathrm{C}$ for AA-5754 and AA-5083, respectively) from ECAP-processed material and from non-ECAP-processed material, conventional forging at $380^{\circ} \mathrm{C}$ and annealed material.

In relation to the aluminium alloys under consideration in this study (AA-5754 and AA-5083), it may be stated that both nanostructured aluminium alloys show better wear behaviour if they are compared with conventional isothermal forging or with forging at low temperature, where these last two study cases show quite similar wear values. The fact that the ECAP-processed aluminium alloys exhibit the best wear behaviour may be explained in terms of the improvement in the mechanical properties that the ECAP process produces. Consequently, it may be pointed out that the isothermal forging process of ECAP-processed AA-5754 and AA-5083 leads to a finer and more homogeneous microstructure compared to the non-ECAP-processed ones. Moreover, forging of ECAP-processed parts leads to an increase in the microhardness of AA-5754 and AA-5083 aluminium alloys of $12.2 \%$ and $10.3 \%$, respectively, which may explain the fact of the improvement in the wear behaviour of the two aluminium alloys under consideration. For both AA-5754 and AA-5083, the case which shows the worst wear behaviour is the one with the annealed initial material.

The FEM simulations carried out in order to calculate both the plastic strain distribution and the damage distribution inside the billets turn out to be very useful to support the design of the experimentation and to predict that no cracks appear at the outer surface of the disks during the isothermal forging process.

Moreover, by using a methodology which is shown in this present study, wear coefficients for the two materials are obtained at different initial states. FEM and experimental results are also compared. From this, it may be observed that there is close agreement between the experimental results and the FEM simulations, where a maximum difference value is obtained between them of around $5 \%$. Therefore, it is possible to affirm that the method developed allows wear coefficients for different materials to be obtained. It may be underlined that the coefficients obtained by this procedure can be used in order to perform wear FEM simulations and thus to predict the wear behaviour of materials. As an example, in the case of the wear coefficient (at 100,000 revolutions) for the ECAP-processed AA-5083, a decrease of $14.0 \%$ (from $3.121 \times 10^{-8} \mathrm{MPa}^{-1}$ to $2.685 \times 10^{-8} \mathrm{MPa}^{-1}$ ) is achieved compared to the non-ECAP-processed one. Moreover, in the case of the ECAP-processed AA-5754, the decrease is $32.4 \%$ (from $2.182 \times 10^{-8} \mathrm{MPa}^{-1}$ to $1.474 \times 10^{-8} \mathrm{MPa}^{-1}$ ). 
Author Contributions: All the authors of this present manuscript have approximately equally contributed to most of the research tasks. However, C.J.L.P., R.L.I., J.P.F.B., J.L.I., D.S.P. and I.P.A. contributed to a great extent in performing the experiments (investigation); C.J.L.P. and R.L.I. contributed to a great extent in conceiving and designing the experiments as well as in analysing the data (formal analysis), and R.L.I., C.J.L.P. and D.S.P. made the FEM simulations (software). All authors have read and agreed to the published version of the manuscript.

Funding: This research was funded by the Spanish Ministry of Science and Innovation (former Spanish Ministry of Economy and Competitiveness) through the Research Project DPI2013-41954-P.

Acknowledgments: The authors of this present research work acknowledge the support given by the Spanish Ministry of Science and Innovation (former Spanish Ministry of Economy and Competitiveness) through the Research Project DPI2013-41954-P. The authors also thank for technical and human support provided by SGIker (UPV/EHU/ERDF, EU).

Conflicts of Interest: The authors declare no conflict of interest.

\section{References}

1. Segal, V.M. Materials processing by simple shear. Mater. Sci. Eng. A 1995, 197, 157-164. [CrossRef]

2. Radhi, H.N.; Aljassani, A.M.H.; Mohammed, M.T. Effect of ECAP on microstructure, mechanical and tribological properties of aluminum and brass alloys: A review. Mater. Today Proc. 2020, 26, 2302-2307. [CrossRef]

3. Sandeep, C.S.; Senetakis, K. Effect of Young's Modulus and Surface Roughness on the Inter-Particle Friction of Granular Materials. Materials 2018, 11, 217. [CrossRef] [PubMed]

4. Ni, J.; Zhu, Z. Experimental Study of Tangential Micro Deflection of Interface of Machined Surfaces. J. Manuf. Sci. Eng. 1999, 123, 365-367. [CrossRef]

5. Sandeep, C.S.; Senetakis, K. An experimental investigation of the microslip displacement of geological materials. Comput. Geotech. 2019, 107, 55-67. [CrossRef]

6. Greenwood, J.A.; Tripp, J.H. The Contact of Two Nominally Flat Rough Surfaces. Proc. Inst. Mech. Eng. 1970, 185, 625-633. [CrossRef]

7. Medina, S.; Nowell, D.; Dini, D. Analytical and Numerical Models for Tangential Stiffness of Rough Elastic Contacts. Tribol. Lett. 2012, 49, 103-115. [CrossRef]

8. Thuong, N.V.; Zuhailawati, H.; Abu Seman, A.A.; Huy, T.D.; Dhindaw, B.K. Microstructural evolution and wear characteristics of equal channel angular pressing processed Semi-Solid-Cast hypoeutectic aluminum alloys. Mater. Des. 2015, 67, 448-456. [CrossRef]

9. El Aal, M.I.A.; El Mahallawy, N.; Shehata, F.A.; El Hameed, M.A.; Yoon, E.Y.; Kim, H.S. Wear properties of ECAP-Processed ultrafine grained Al-Cu alloys. Mater. Sci. Eng. A 2010, 527, 3726-3732. [CrossRef]

10. El Aal, M.I.A. The effect of the Pre-Homogenization treatment on the fracture characteristics and wear properties of ECAPed Al-Cu alloys. Mater. Sci. Eng. A 2012, 539, 308-323. [CrossRef]

11. Chegini, M.; Fallahi, A.; Shaeri, M.H. Effect of Equal Channel Angular Pressing (ECAP) on Wear Behavior of Al-7075 Alloy. Procedia Mater. Sci. 2015, 11, 95-100. [CrossRef]

12. Manjunath, G.; Bhat, K.U.; Kumar, G.V.P. Dry sliding wear behaviour of Al-5Zn-2Mg alloy processed by severe plastic deformation. Mater. Today Proc. 2020, in press. [CrossRef]

13. El Aal, M.I.A.; Kim, H.S. Wear properties of high pressure torsion processed ultrafine grained Al-7\%Si alloy. Mater. Des. 2014, 53, 373-382. [CrossRef]

14. Li, J.; Wongsa-Ngam, J.; Xu, J.; Shan, D.; Guo, B.; Langdon, T.G. Wear resistance of an Ultrafine-Grained $\mathrm{Cu}$-Zr alloy processed by Equal-Channel angular pressing. Wear 2015, 326, 10-19. [CrossRef]

15. Zhilyaev, A.P.; Shakhova, I.; Belyakov, A.; Kaibyshev, R.; Langdon, T.G. Wear resistance and electroconductivity in copper processed by severe plastic deformation. Wear 2013, 305, 89-99. [CrossRef]

16. Purcek, G.; Yanar, H.; Shangina, D.; Demirtas, M.; Bochvar, N.; Dobatkin, S. Influence of high pressure Torsion-Induced grain refinement and subsequent aging on tribological properties of Cu-Cr-Zr alloy. J. Alloys Compd. 2018, 742, 325-333. [CrossRef]

17. Purcek, G.; Yanar, H.; Demirtas, M.; Shangina, D.; Bochvar, N.; Dobatkin, S. Microstructural, mechanical and tribological properties of Ultrafine-Grained $\mathrm{Cu}-\mathrm{Cr}-\mathrm{Zr}$ alloy processed by high pressure torsion. J. Alloys Compd. 2020, 816, 152675. [CrossRef]

18. Stolyarov, V.; Shuster, L.; Migranov, M.; Valiev, R.; Zhu, Y. Reduction of friction coefficient of Ultrafine-Grained CP titanium. Mater. Sci. Eng. A 2004, 371, 313-317. [CrossRef] 
19. Wang, C.T.; Gao, N.; Gee, M.; Wood, R.J.; Langdon, T.G. Processing of an Ultrafine-Grained titanium by High-Pressure torsion: An evaluation of the wear properties with and without a TiN coating. J. Mech. Behav. Biomed. Mater. 2013, 17, 166-175. [CrossRef]

20. Patil, A.; Bontha, S.; Ramesh, M. Effect of ECAP on sliding wear behaviour of Mg-Zn-Gd-Zr alloy. Mater. Today Proc. 2020, 20, 97-102. [CrossRef]

21. Huang, S.-J.; Semenov, V.I.; Shuster, L.S.; Lin, P.-C. Tribological properties of the Low-Carbon steels with different Micro-Structure processed by heat treatment and severe plastic deformation. Wear 2011, 271, 705-711. [CrossRef]

22. Luis Pérez, C.J.; Luri Irigoyen, R.; Fuertes Bonel, J.P.; León Iriarte, J.; Salcedo Pérez, D.; Puertas Arbizu, I. Experimental and FEM Analysis of Wear Behaviour in AA5083 Ultrafine-Grained Cams. Metals 2020, 10, 479. [CrossRef]

23. León, J.; Luis, C.J.; Fuertes, J.P.; Puertas, I.; Luri, R.; Salcedo, D. A Proposal of a Constitutive Description for Aluminium Alloys in both Cold and Hot Working. Metals 2016, 6, 244. [CrossRef]

24. Biswas, S.; Kailas, S. Strain rate response and wear of metals. Tribol. Int. 1997, 30, 369-375. [CrossRef]

25. Kailas, S.V.; Biswas, S. Strain rate response and its effect in plane strain abrasion of metals by a wedge. Wear 1995, 184, 23-32. [CrossRef]

26. Chelliah, N.; Kailas, S.V. Synergy between Tribo-Oxidation and strain rate response on governing the dry sliding wear behavior of titanium. Wear 2009, 266, 704-712. [CrossRef]

27. Kumar, V.; Li, L.; Gui, H.; Wang, X.; Huang, Q.; Li, Q.; Mokdad, F.; Chen, D.; Li, D.Y. Tribological properties of AZ31 alloy Pre-Deformed at low and high strain rates via the work function. Wear 2018, 414-415, 126-135. [CrossRef]

28. Rajaram, G.; Kumaran, S.; Rao, T.S. High temperature tensile and wear behaviour of aluminum silicon alloy. Mater. Sci. Eng. A 2010, 528, 247-253. [CrossRef]

29. Rajaram, G.; Kumaran, S.; Rao, T.S.; Kamaraj, M. Studies on high temperature wear and its mechanism of Al-Si/graphite composite under dry sliding conditions. Tribol. Int. 2010, 43, 2152-2158. [CrossRef]

30. Kumar, P.R.S.; Kumaran, S.; Rao, T.S.; Natarajan, S. High temperature sliding wear behavior of Press-Extruded AA6061/fly ash composite. Mater. Sci. Eng. A 2010, 527, 1501-1509. [CrossRef]

31. Fernandes, G.; Zanotto, P.; Sinatora, A. Contribution on understanding the friction film development in the performance of a dry automotive clutch system. Wear 2015, 342, 364-376. [CrossRef]

32. Xi, Y.; Björling, M.; Shi, Y.; Mao, J.; Larsson, R. Application of an inclined, spinning Ball-On-Rotating disc apparatus to simulate railway wheel and rail contact problems. Wear 2017, 374, 46-53. [CrossRef]

33. Purcek, G.; Savaşkan, T.; Kucukomeroglu, T.; Murphy, S. Dry sliding friction and wear properties of Zinc-Based alloys. Wear 2002, 252, 894-901. [CrossRef]

34. Kim, N.H.; Won, D.; Burris, D.; Holtkamp, B.; Gessel, G.R.; Swanson, P.; Sawyer, W.G. Finite element analysis and experiments of metal/metal wear in oscillatory contacts. Wear 2005, 258, 1787-1793. [CrossRef]

35. Salcedo, D.; Luis, C.J.; Luri, R.; Puertas, I.; León, J.; Fuertes, J.P. Design and Mechanical Properties Analysis of AA5083 Ultrafine Grained Cams. Metals 2017, 7, 116. [CrossRef]

36. León, J.; Salcedo, D.; Murillo, Ó.; Luis, C.J.; Fuertes, J.P.; Puertas, I.; Luri, R. Mechanical Properties Analysis of an Al-Mg Alloy Connecting Rod with Submicrometric Structure. Metals 2015, 5, 1397-1413. [CrossRef]

37. ASM Handbook; Forming and Forging (Volume 14), Ed.; ASM International: Materials Park, OH, USA, 1988.

38. Luri, R.; Fuertes, J.P.; Luis, C.J.; Salcedo, D.; Puertas, I.; León, J. Experimental modelling of critical damage obtained in Al-Mg and Al-Mn alloys for both annealed state and previously deformed by ECAP. Mater. Des. 2016, 90, 881-890. [CrossRef]

39. Archard, J.F. Contact and Rubbing of Flat Surfaces. J. Appl. Phys. 1953, 24, 981-988. [CrossRef]

40. Archard, J.F.; Hirst, W. The wear of metals under unlubricated conditions. Proc. R. Soc. Lond. Ser. A Math. Phys. Sci. 1956, 236, 397-410. [CrossRef]

(C) 2020 by the authors. Licensee MDPI, Basel, Switzerland. This article is an open access article distributed under the terms and conditions of the Creative Commons Attribution (CC BY) license (http://creativecommons.org/licenses/by/4.0/). 